\title{
Should investors include bitcoin in their portfolios? A portfolio theory approach
}

Article

Accepted Version

Creative Commons: Attribution-Noncommercial-No Derivative Works 4.0

Platanakis, E. and Urquhart, A. (2020) Should investors include bitcoin in their portfolios? A portfolio theory approach. The British Accounting Review, 52 (4). 100837. ISSN 08908389 doi: https://doi.org/10.1016/j.bar.2019.100837 Available at https://centaur.reading.ac.uk/84380/

It is advisable to refer to the publisher's version if you intend to cite from the work. See Guidance on citing.

To link to this article DOI: http://dx.doi.org/10.1016/j.bar.2019.100837

Publisher: Elsevier

All outputs in CentAUR are protected by Intellectual Property Rights law, including copyright law. Copyright and IPR is retained by the creators or other copyright holders. Terms and conditions for use of this material are defined in the End User Agreement.

\section{www.reading.ac.uk/centaur}

\section{CentAUR}

Central Archive at the University of Reading

Reading's research outputs online 


\title{
Should Investors Include Bitcoin in Their Portfolios? A Portfolio Theory Approach
}

\author{
Emmanouil Platanakis* \\ Andrew Urquhart ${ }^{\#}$
}

17 June 2019

* School of Management, University of Bath, Claverton Down, Bath, BA2 7AY, UK, email:
E.Platanakis@,bath.ac.uk, Tel: +44 (0) 1225386207
\# ICMA Centre, Henley Business School, University of Reading, Whiteknights, Reading, Berkshire
RG66BA, UK, email: a.j.urquhart@,icmacentre.ac.uk

We wish to thank Professor Charles Sutcliffe (University of Reading), Professor Mark Shackleton (Lancaster University), 2 anonymous reviewers and the editor of this journal for their valuable comments on earlier versions of this paper as well as participants at the 25th Annual Global Finance Conference (Paris), the Cryptocurrency Research Conference 2018 (Cambridge, UK), the 4th Quantitative Finance \& Risk Analysis (QFRA) Symposium (Mykonos, Greece), the 25th International Conference on Quantitative Finance (Forecasting Financial Markets - Said Business School, University of Oxford) and the British Accounting and Finance Association (BAFA) Conference 2019 (University of Birmingham). 


\title{
Should Investors Include Bitcoin in Their Portfolios? A Portfolio Theory Approach
}

\begin{abstract}
Many papers in recent years have examined the benefits of adding alternative assets to traditional portfolios containing stocks and bonds. Bitcoin has emerged as a new alternative investment for investors which has attracted much attention from the media and investors alike. However relatively little is known about the investment benefits of Bitcoin and therefore this paper examines the benefit of including Bitcoin in a traditional benchmark portfolio of stocks and bonds. Specially, we employ data up to June 2018 and analyse the potential out-of-sample portfolio benefits resulting from including Bitcoin in a stock-bond portfolio for a range of eight popular asset allocation strategies. The out-of-sample analysis shows that, across all different asset allocation strategies and risk aversions, the benefits of Bitcoin are quite considerable with substantially higher risk-adjusted returns. Our results are robust to rolling estimation windows, the incorporation of transaction costs, the inclusion of a commodity portfolio, alternative indices, short-selling as well as two additional optimization techniques including higher moments with (and without) variancebased constraints (VBCs). Therefore, our results suggest that investors should include Bitcoin in their portfolio as it generates substantial higher risk-adjusted returns.
\end{abstract}

Keywords: FinTech; Bitcoin; Diversification; Out-of-Sample Performance; Portfolio Optimization 


\section{Introduction}

First proposed by Nakamoto (2008), Bitcoin is a peer-to-peer electronic cash system which allows online payments to be sent direct from one individual to another without going through a financial institution and therefore is frequently argued to be an alternative currency. The key features of Bitcoin are that it has no physical representation, association with any authority and is built using complex mathematics and computational methods. The value of Bitcoin is not based on any country economy (unlike traditional currencies) or on some tangible assets (unlike commodities) and is instead based on the security of the algorithm, traceability of the transactions and the precedence of each Bitcoin. Further, the exact number of circulating Bitcoins in the market is known and therefore its money supply is constant providing an incentive for owners to keep them and not trade them for goods or services (Kristoufek 2015). The dramatic growth of Bitcoin (and other cryptocurrencies) challenges politicians and policy makers as Bitcoin and FinTech create an alternative environment for businesses. Bitcoin experienced a huge surge in price during 2017, although the during the first half of 2018, the price has fallen quite considerably. ${ }^{1}$ However there is evidence that this surge in price has nothing to do with Bitcoins ability to be medium exchange, but as an investment, see for instance Baur et al (2018), and many others.

There is an ever-growing literature examining Bitcoin, with influential work by Gandal et al (2018) documenting the price manipulation of Bitcoin, while Foley et al (2019) show the amount illegal activity conducted through Bitcoin. Recently, Makarov and Schoar (2019) show the arbitrage opportunities in cryptocurrency markets. A large area of research has studied the relationship of Bitcoin with other financial assets. Dwyer (2015) shows that the average monthly volatility of Bitcoin is higher than that of gold or a set of foreign currencies while Urquhart (2016) shows that Bitcoin returns are inefficient, which is supported by Nadarajah and Chu (2017) and Bariviera (2017). Cheah and Fry (2015) show that, over the period July 2010 to July 2014, Bitcoin is prone to substantial speculative bubbles, while Balcilar et al (2017) show that Bitcoin volume can predict returns except in bear and bull market regimes. Katsiampa (2017) examines various GARCH models and shows the importance of having both a short-run and long-run component of the conditional variance, while Urquhart (2017) shows significant price clustering of Bitcoin prices at round numbers. Shen et al (2019) show that the number of tweets of Bitcoin is significant driver of trading volume and realized volatility of cryptocurrencies while Grobys and Sapkota (2019) show no evidence of significant momentum profits in cryptocurrency markets.

\footnotetext{
${ }^{1}$ See Figure 2 for a time-series graph of the price of Bitcoin during our sample period.
} 
These papers have studied the price dynamics of Bitcoin, but another strand of literature examines the relationship of Bitcoin to other financial assets. Dyhrberg (2016) shows that Bitcoin can act as a hedge against the US dollar and the UK stock market, sharing similar hedging capabilities to gold. Bouri et al (2017a) employ a quantile regression approach to analyse the relationship between gold and global uncertainty, and show that Bitcoin can hedge against global uncertainty at short investment horizons and in bull regimes. Also, Bouri et al (2017b) employ a DCC model and show limited evidence of the hedging and safe haven properties of Bitcoin, although it can still be an effective diversifier. Guesmi et al (2018) show that Bitcoin can be a hedge against many different financial assets. Therefore there is evidence that Bitcoin has some hedging capabilities and diversification benefits. ${ }^{2}$ Klein et al (2018) show that Bitcoin offers no hedging capabilities like gold which also holds for the brad cryptocurrency index CRIX while Urquhart and Zhang (2019) show that Bitcoin can be a hedge at an intraday level for the CHF, EUR and GBP currencies. Recently, Platanakis and Urquhart (2019) show the importance of estimation risk when creating a portfolio of cryptocurrencies.

The inclusion of alternative investments in traditional stock-bond portfolios has been studied in some detail in the literature, with mixed results. For instance, Gorton and Rouwenhorst (2006), Hillier et al (2006), Conover et al (2010) and Gao and Nardari (2018) all find that adding commodities to a benchmark portfolio adds value. Contrasting evidence however has been found by Erb and Harvey (2006), Daskalaki and Skiadopoulos (2011), Bessler and Wolff (2015) and Platanakis et al (2019) who all find that commodities offer no additional value, while Liu et al. (2018) find that some commodities provide diversification benefits and some others may not be useful for portfolio diversification. There is growing research examining the portfolio diversification benefits of Bitcoin, where Brière et al (2015) show that the correlation between bitcoin and other assets is exceptionally low and the inclusion of bitcoin dramatically improves the risk-adjusted returns of the portfolios. Eisl et al (2015) implement a CVaR approach and show that Bitcoin should be included in optimal portfolios as its inclusion leads to better risk-return ratios while Wu and Pandey (2014) show that Bitcoin may not be useful as a currency but can play an important role in enhancing the efficiency of an investor's portfolio. Recently, Kajtazi and Moro (2019) examine the role of Bitcoin in portfolios of US, European and Chinese assets and support previous findings in showing that Bitcoin improves portfolio performance by increasing returns, and not be reducing risk. However, these papers only study Bitcoin over a short period of time

\footnotetext{
${ }^{2}$ For a detailed review of the literature on Bitcoin and other cryptocurrencies, see Corbet al (2019).
} 
and some exclude dramatic growth in Bitcoin trading volume and price in 2017, as well as the subsequent turmoil in 2018. Further, these papers mainly study in-sample estimation and through only one portfolio optimization technique.

So should investors hold Bitcoin, and what effect does holding Bitcoin have on portfolio performance? This paper attempts to answer this question in a pure out-of-sample setting. We investigate whether Bitcoin adds value to a stock-bond portfolio by employing eight different portfolio construction techniques. Portfolio theory is highly sensitive to estimation risk that may overstate (understate) returns (risk). In practice this means that optimal portfolios constructed via the classical Markowitz mean-variance optimization can be unstable with a weak out-of-sample performance and this phenomenon has been well-substantiated in the portfolio theory literature (Ziemba and Mulvey, 1998; Kolm et al, 2014; Levy and Roll, 2010; Levy and Levy, 2014; Levy and Simaan, 2016; Carroll et al, 2016). For this reason, we employ eight sophisticated portfolio construction methods to determine the benefit of including Bitcoin in a stock-bond portfolio. We find that including Bitcoin to a portfolio in an out-of-sample setting substantially increases excess returns and increases the Sharpe, Omega and Sortino ratios. We also show that these findings are robust to expanding and rolling estimation windows, transaction costs, the 2018 downturn in Bitcoin, different values of risk aversion, alternative indices, as well as to alternative portfolio construction techniques including higher moments with (and without) variance-based constraints (VBCs) of Levy and Levy (2014) and to simulated data and when short selling is permitted. Finally, we also show that Bitcoin adds value above and beyond commodities by including the GSCI commodity index in the original portfolio, where risk-adjusted returns are substantially higher after the inclusion of Bitcoin.

Therefore, this study contributes to the literature in several important ways. First, we comprehensively analyse the out-of-sample diversification benefits from adding Bitcoin to a benchmark portfolio of stocks and bonds. The media and investor interest in Bitcoin has grown vastly in the last 8 years, and this paper details whether including Bitcoin in a stock-bond portfolio can improve excess returns and the risk-adjusted returns. Second, we implement 8 different and popular asset allocation strategies to overcome any concern that any one asset allocation strategy is skewing our results. We also include two further models which encompass higher moments as a robustness check. Third, since Bitcoin prices can differ across exchanges, we employ two different Bitcoin prices, namely the CoinDesk price and the Datastream price (Bitstamp) in order to avoid any concern regarding the choice of Bitcoin price. Fourth, we evaluate the performance 
of a pure out-of-sample estimation on a risk-adjusted returns basis inclusive of transaction costs to provide realistic results for an investor who includes Bitcoin in their asset allocation. Fifth, we show that our results are robust to the inclusion of the most popular commodity index to the benchmark portfolio. Finally, we include the turbulent period of 2018 in our analysis to show that even during this period, Bitcoin improves the risk-adjusted returns of portfolios.

The rest of this paper is organized as follows. Section 2 presents the data and methodology, while Section 3 describes the empirical results, and Section 4 summarizes our findings and provides conclusions.

\section{Data and Methodology}

\subsection{Data}

We collect weekly Bitcoin prices from CoinDesk from October 2011 to June 2018, as well as the Bitstamp Bitcoin price. We choose this sample period since trading volume of Bitcoin before October 2011 is relatively low while the end date is chosen as the date the main work of this paper was carried out. ${ }^{3}$ We select CoinDesk Bitcoin price index since a number of academic papers have already employed CoinDesk Bitcoin price index (for instance Cheah and Fry 2015; Katsiampa 2017). It is also the average price across leading global exchanges that meet specific criteria stated by CoinDesk. ${ }^{4}$ For a robustness check, we analyse the Bitstamp Bitcoin price, which is highly liquid, one of the longest running exchanges and is the exchange that Datastream uses to provide a Bitcoin price to their customers. We rebalance our portfolio on a weekly basis since monthly data would not provide enough observations for an out-of-sample analysis while daily prices would result in a large turnover and thus high transaction costs.

To analyse the benefits of Bitcoin, we take the perspective of a U.S. investor holding a portfolio consisting of stocks and bonds as in Daskalaki and Skiadopoulos (2011). We use the S\&P 500 index for stocks and the Barclays US Aggregate for bonds, both collected from Bloomberg, while we collect the 1-month risk-free rate from the database of Kenneth French for our risk-adjusted return calculations. ${ }^{5}$

\footnotetext{
${ }^{3}$ Unlike earlier studies that examined the bull market of Bitcoin, our sample period also includes the bear market period and therefore provides a more comprehensive review of the performance of Bitcoin in a portfolio setting.

${ }^{4}$ For more details, see https://www.coindesk.com/price/bitcoin-price-index/.

${ }^{5}$ Found at http://mba.tuck.dartmouth.edu/pages/faculty/ken.french/data library.html.
} 


\subsection{Asset Allocation Strategies}

There are several portfolio optimization techniques which could be used for optimizing our portfolios, and we choose eight of those most popular and commonly considered by portfolio managers. Each strategy has a different rationale which may result to different weights being allocated to each asset, which is beneficial to us in providing a comprehensive account of the value of adding Bitcoin to a portfolio. Applying a diverse variety of portfolio models reduces the issue of estimation risk in the input parameters of the portfolio selection process (Levy and Levy 2014; Kolm et al 2014), and also provides robustness to our conclusions. The eight asset allocation strategies are as follows:

\subsubsection{Markowitz, Mean-Variance Portfolio Optimization (Markowitz)}

In the mean-variance portfolio optimization framework of Markowitz (1952), investors optimize the trade-off between the mean and variance of portfolio returns. Markowitz (2014) also points out that over a half-century research in the field has been generally supportive to mean-variance analysis. To facilitate this model, we compute the vector of portfolio weights $(\mathbf{x})$, by maximizing the following utility function (quadratic) with respect to $\mathbf{x}$ by using the sample mean $(\boldsymbol{\mu})$ and covariance matrix $(\Sigma)$ :

$$
U=\mathbf{x}^{\mathrm{T}} \boldsymbol{\mu}-\frac{\lambda}{2} \mathbf{x}^{\mathrm{T}} \boldsymbol{\Sigma} \mathbf{x}
$$

where the parameter $\lambda$ represents the investor's relative risk aversion. We also impose non-short selling constraints $\left(\mathrm{x}_{i} \geq 0, \forall i\right)$ and normalization of portfolio weights $\left(\sum_{i=1}^{N} \mathrm{x}_{i}=1\right)$. Hence, the optimization problem is described as follows:

$$
\begin{array}{ll}
\max _{\mathbf{x}} & \left\{\mathbf{x}^{\mathrm{T}} \boldsymbol{\mu}-\frac{\lambda}{2} \mathbf{x}^{\mathrm{T}} \boldsymbol{\Sigma} \mathbf{x}\right\} \\
\text { s.t. } & \mathrm{x}_{i} \geq 0, \forall i \\
& \sum_{i=1}^{N} \mathrm{x}_{i}=1
\end{array}
$$




\subsubsection{Markowitz Mean-Variance Portfolio Optimization with Gens (Markowitz, with Gens)}

The Markowitz Mean-Variance Portfolio Optimization with Gens approach combines Markowitz optimization and lower generalized constraints to decrease further the negative effect of estimation errors when computing the optimal portfolio weights. The lower the generalized constraints are as follows:

$$
\mathbf{x} \geq \alpha_{\text {lower }} \mathbf{1} \text {, with } \alpha_{\text {lower }} \in[0,1 / N]
$$

where 1 denotes a column vector $(\mathrm{Nx} 1)$ of ones. Please note that the equally weighted portfolio $(1 / N)$ is obtained if $\alpha_{\text {lower }}=1 / N$, while we get the shortsale-constrained portfolio if $\alpha_{\text {lower }}=0$. We use the middle of the range and set $\alpha_{\text {lower }}=(0+1 / N) / 2=\frac{1}{2 N}$ as in DeMiguel et al. (2009), and many others.

\subsubsection{Bayes-Stein Shrinkage Portfolio Approach (Bayes-Stein)}

The Bayes-Stein shrinkage portfolio approach (Jorion 1986) is a robust way of dealing with estimation risk in the optimal portfolio selection process and has been very widely used in the relevant academic literature, see for instance Board and Sutcliffe (1994), DeMiguel et al (2009), Bessler et al (2017) and Platanakis and Sutcliffe (2017), amongst others. The Bayes-stein approach is based on the idea of "shrinkage estimation" and computes the column vector of mean returns $\left(\boldsymbol{\mu}_{\mathrm{BS}}\right)$ as follows:-

$$
\boldsymbol{\mu}_{\mathrm{BS}}=(1-\mathrm{g}) \boldsymbol{\mu}+\mathrm{g} \mu_{\mathrm{G}} \mathbf{1}
$$

where the shrinkage factor $g(0 \leq g \leq 1)$ is given by:-

$$
\mathrm{g}=\frac{\mathrm{N}+2}{(\mathrm{~N}+2)+T\left(\boldsymbol{\mu}-\mu_{\mathrm{G}} \mathbf{1}\right)^{\mathrm{T}} \Sigma^{-1}\left(\mu-\mu_{\mathrm{G}} \mathbf{1}\right)} .
$$


$\mu_{\mathrm{G}}$ denotes the expected return of the minimum variance portfolio (allowing short-selling) and $T$ represents the length of the corresponding estimation period. The covariance matrix of asset returns $\left(\boldsymbol{\Sigma}_{\mathrm{BS}}\right)$ is given by:-

$$
\boldsymbol{\Sigma}_{\mathrm{BS}}=\left(\frac{T+\varphi+1}{T+\varphi}\right) \boldsymbol{\Sigma}+\frac{\varphi}{T(T+\varphi+1)} \frac{\mathbf{1 1}^{\mathrm{T}}}{\mathbf{1}^{\mathrm{T}} \boldsymbol{\Sigma}^{-1} \mathbf{1}},
$$

where

$$
\varphi=\frac{\mathrm{N}+2}{\left(\boldsymbol{\mu}-\mu_{\mathrm{G}} \mathbf{1}\right)^{\mathrm{T}} \Sigma^{-1}\left(\boldsymbol{\mu}-\mu_{\mathrm{G}} \mathbf{1}\right)} .
$$

We use the Bayes-Stein estimates $\left(\boldsymbol{\mu}_{\mathrm{BS}}, \boldsymbol{\Sigma}_{\mathrm{BS}}\right)$ in the same optimization process and subject to the same constraints as in the Markowitz mean-variance model described in equation 2.

\subsubsection{Bayes-Stein Shrinkage Portfolio Approach with Gens (Bayes-Stein with Gens)}

This approach combines the Bayes-Stein Shrinkage Portfolio Approach with the lower generalized constraints described above.

\subsubsection{Black-Litterman Portfolio Construction Model (Black-Litterman)}

The Black-Litterman portfolio optimization approach is an alternative approach for dealing with estimation errors in the portfolio construction process, and has recently attracted great attention in both academia and the financial industry, see for instance Kolm et al (2014), Bessler and Wolff (2015), Platanakis and Sutcliffe (2017), Platanakis et al (2019), Oikonomou et al (2018) and Silva, et al. (2017), amongst others. The Black-Litterman approach combines two sources of information: the investor's "views" on asset returns (subjective return estimates) and the reference (or benchmark) portfolio used for the computation of "neutral" ("implied") returns.

The column vector of implied excess-returns $(\mathbf{H})$ is given by (Black and Litterman 1992):-

$$
\mathbf{H}=\lambda \Sigma \mathbf{x}^{\text {Reference }},
$$


where the column vector $\mathbf{x}^{\text {Reference }}$ contains the weights of the reference (benchmark) portfolio. Following Bessler et al (2017) and Platanakis et al (2018), amongst other, we set $\mathbf{x}^{\text {Reference }}$ to the equally-weighted portfolio $\left(\mathbf{x}^{\text {Reference }}=\frac{1}{N} \mathbf{1}\right)$. This is the case where investors consider that asset return estimates involve a high degree of estimation risk.

The Black-Litterman model computes the column vector (posterior estimate) of mean returns $\left(\boldsymbol{\mu}_{\mathrm{BL}}\right)$ as follows:-

$$
\boldsymbol{\mu}_{\mathrm{BL}}=\left[(c \boldsymbol{\Sigma})^{-1}+\boldsymbol{P}^{\mathrm{T}} \boldsymbol{\Omega}^{-1} \boldsymbol{P}\right]^{-1}\left[(c \boldsymbol{\Sigma})^{-1} \mathbf{H}+\boldsymbol{P}^{\mathrm{T}} \boldsymbol{\Omega}^{-1} \mathbf{Q}\right]
$$

where $\boldsymbol{P}$ is a binary matrix with "ones" only in its leading diagonal indicating which assets are involved in each view, $\mathbf{Q}$ is a column vector that contains the investor's views (subjective returns) and the parameter $\mathcal{C}$ represents a measure of reliability for the implied excess-returns in the column vector $(\mathbf{H})$. To this end, we use the mean of the values used by previous studies in the literature and set $c=0.1625$ as in Platanakis and Sutcliffe (2017). Furthermore, the diagonal matrix $\boldsymbol{\Omega}$ quantifies the reliability measures for each asset and is computed as follows (Meucci 2010):-

$$
\boldsymbol{\Omega}=\frac{1}{\delta} \boldsymbol{P} \Sigma \boldsymbol{P}^{\mathrm{T}}
$$

In addition, we set $1 / \delta$ to unity following Meucci (2010) and Platanakis and Sutcliffe (2017), amongst others, and use the mean asset returns over the corresponding estimation period in selecting the investor's views for the column vector $\boldsymbol{Q}$.

Finally, we follow Satchell and Scowcroft (2000) and many other studies by computing the posterior covariance matrix $\left(\boldsymbol{\Sigma}_{\mathrm{BL}}\right)$ as follows:-

$$
\boldsymbol{\Sigma}_{\mathrm{BL}}=\boldsymbol{\Sigma}+\left[(c \boldsymbol{\Sigma})^{-1}+\boldsymbol{P}^{\mathrm{T}} \boldsymbol{\Omega}^{-1} \boldsymbol{P}\right]^{-1}
$$


We use the Black-Litterman estimates $\left(\boldsymbol{\mu}_{\mathrm{BL}}, \boldsymbol{\Sigma}_{\mathrm{BL}}\right)$ in the same optimization process and subject to the same constraints as in the Markowitz mean-variance model described in equation 2.

\subsubsection{Minimum V ariance with Lower Generalized Constraints (Minimum-Variance with Gens)}

For this technique, we minimize the portfolio variance $\left(\mathbf{x}^{\mathrm{T}} \boldsymbol{\Sigma} \mathbf{x}\right)$ subject to short-selling constraints $\left(\mathrm{x}_{i} \geq 0, \forall i\right)$, normalization of portfolio weights $\left(\sum_{i=1}^{N} \mathrm{x}_{i}=1\right)$ and lower generalized constraints. This portfolio technique is independent of the parameter $\lambda$ (relative risk aversion).

\subsubsection{Equally Weighted Portfolio (1/N with re-balancing)}

A portfolio weight of $1 / \mathrm{N}$ is assigned to each portfolio asset. We use $1 / \mathrm{N}$ with re-balancing as in DeMiguel et al (2009) and Platanakis et al (2019).

\subsubsection{Combination of Portfolio Techniques (3-fund portfolio combination)}

Inspired by Kan and Zhou (2007) and DeMiguel et al (2009), amongst others, and in an attempt to eliminate further the negative effects of estimation risk in the portfolio construction process, we also apply a method that shrinks the portfolio weights by considering combinations of portfolios. More specifically, we combine the equally-weighted portfolio $\left(\mathbf{x}^{1 / \mathrm{N}}\right)$, the minimumvariance portfolio $\left(\mathbf{x}^{\mathrm{MV}}\right)$ and the Markowitz mean-variance portfolio ( $\left.\mathbf{x}^{\text {Markowitz }}\right)$. All the individual portfolios used in this framework $\left(\mathbf{x}^{1 / \mathrm{N}}, \mathbf{x}^{\text {Markowitz }} \& \mathbf{x}^{\mathrm{MV}}\right)$ are subject to short selling constraints and normalization of portfolio weights. We compute the "optimal" combination of the three individual strategies $\left(\mathbf{x}^{1 / \mathrm{N}}, \mathbf{x}^{\text {Markowitz }} \& \mathbf{x}^{\mathrm{MV}}\right):-$

$$
\mathbf{x}^{1 / \mathrm{N}-\mathrm{MV}-\mathrm{TP}}=\alpha_{1} \mathbf{x}^{1 / \mathrm{N}}+\alpha_{2} \mathbf{x}^{\mathrm{MV}}+\alpha_{3} \mathbf{x}^{\mathrm{TP}}, \quad \alpha_{1}, \alpha_{2}, \alpha_{3} \geq 0
$$

by maximizing the expected quadratic utility function as in the optimization problem described in (2) for the Markowitz mean-variance problem and subject to the same constraints. 
The eight different portfolio construction models employed for the core analysis are summarized in Table 1.

\subsection{Out-of-sample estimation procedure}

Throughout our analysis, we employ an out-of-sample estimation process. An in-sample setting would implicitly assume perfect forecasts of the input parameters, but in practice, forecasts are subject to estimation errors, see for instance Welch and Goyal (2008), and many others. Therefore, a more realistic evaluation of the portfolio gains and diversification benefits from Bitcoin rests in an out-of-sample procedure. Here, an investor has to compute the asset weights at time $(t)$ for the subsequent periods $[t, t+1]$ using only data available at time $(t)$. For the core analysis, we follow Board and Sutcliffe (1994) and Tu (2010) by employing an expanding window approach for computing the means and the covariance matrix. This procedure is expected to produce more stable estimates over the time horizon. Specifically, we employ a 52-week expanding window and estimate the optimal portfolio weights for each portfolio model by using data up to and including time $t$ (where $t \geq 52$ ). We then apply these asset weights to compute the actual (out-of-sample) portfolio returns for the next time period $(t+1)$, and repeat this process by moving our sample one week forward until the end of our sample period.

For robustness purposes, we also implement the rolling window approach as in Bessler and Wolff (2015), and many others. This procedure involves a 52-week rolling window for computing the mean returns, while we keep the expanding window for the covariance matrix. This is because we expect that a rolling window may be more responsive to structural breaks for the case of mean returns, while the correlation structure is often more stable over time in comparison to mean returns estimates, see also discussion in Bessler et al (2017). We also solve each case for three different levels of risk aversion and hence our analysis allows an assessment on whether diversification benefits differ with differing risk aversion. These values of $\lambda$ used in our study represent respectively the aggressive $(\lambda=2)$, moderate $(\lambda=5)$ and conservative investors $(\lambda=10)$.

\subsection{Performance Metrics}

We compute the portfolios average out-of-sample return and volatility, as well as the Sharpe ratio which is computed as follows (Sharpe 1966):- 


$$
S R=\frac{\bar{R}_{p}-\bar{R}_{f}}{\sigma_{p}},
$$

where $\bar{R}_{p}-\bar{R}_{f}$ represents the average portfolio return in excess of the risk-free rate computed over the entire out-of-sample period, and $\sigma_{p}$ is the corresponding portfolio standard deviation estimated over the same investment period. However, the Sharpe ratio has its limitations, and as Smetters and Zhang (2014) argue, the Sharpe ratio may face difficulties in providing robust and correct rankings when portfolio returns are not normally distributed. ${ }^{6}$

Therefore we also estimate the Omega ratio (Shadwick and Keating 2002) and the Sortino ratio (Sortino and van der Meer 1991) as additional performance metrics. The Omega ratio, which is also known as a gain-loss ratio, is defined as follows:

$$
\text { Omega }=\frac{\frac{1}{\mathrm{~T}} \sum_{t=1}^{\mathrm{T}} \max \left(0,+R_{p, t}\right)}{\frac{1}{\mathrm{~T}} \sum_{t=1}^{\mathrm{T}} \max \left(0,-R_{p, t}\right)} .
$$

The main advantage of the Omega ratio is its distribution-free nature since it does not rely on any assumption about the distribution of returns. The Sortino ratio is similar to the Sharpe ratio but only considers the standard deviation of downside excess returns rather than the standard deviation of all excess returns, such that:

$$
\text { Sortino }=\frac{\bar{R}_{p}-\bar{R}_{f}}{D R_{p}},
$$

where $D R_{p}$ denotes the downside risk of a portfolio. ${ }^{7}$

\footnotetext{
${ }^{6}$ For a discussion on the issues with the Sharpe ratio, see also Platanakis et al (2019).

${ }^{7}$ We also calculate a number of alternative performance metrics such as the CER, VaR, Dowd ratio, EDD, MDD, Sterling ratio and Calmar ratio. They are available upon request from the corresponding author.
} 


\section{Empirical Results}

In this section, we present the empirical results where we first present the descriptive statistics of the data employed in this study. The analysis of the out-of-sample diversification benefits of Bitcoin for the various asset allocation techniques employed in thus study are then presented for the expanding as well as the rolling window framework. We also provide the results inclusive of transaction costs, and as a robustness check employ the Bitstamp Bitcoin price instead of the CoinDesk Bitcoin price as well employing portfolio selection with higher moments. We also report the asset weights of the various portfolios and examine whether Bitcoin adds value above that of commodities. Further, we report the results with simulated data and when using the CRIX index instead of Bitcoin as robustness checks. Finally, we provide the results when allowing for short sales.

\subsection{Descriptive Statistics}

Panel A of Table 2 reports the descriptive statistics of the returns employed in this study. Both Bitcoin returns have the largest mean return, as well as the highest standard deviation. Both the S\&P 500 and U.S. bonds have negative skewness, while the risk-free asset and both Bitcoin prices experience positive skewness. All series except U.S. bonds have excess kurtosis and therefore a leptokurtic distribution. Both Bitcoin prices have similar characteristics indicating that the difference between the two exchanges is minimal. Panel B of Table 2 reports the correlation matrix between our variables where we can see that the correlation between the S\&P500 and both U.S. bonds and the risk-free asset is negative, while U.S. bonds and the risk-free asset have a small positive correlation. However, the correlation between the both Bitcoin prices and the S\&P500 is positive, but fairly small indicating possible diversification benefits. Further, the correlation between both Bitcoin prices and U.S. bonds is negative, suggesting that there may be some diversification benefits when adding Bitcoin to our stock-bond portfolio. The only significant correlation in our matrix is between our two Bitcoin prices (correlation of 0.98) indicating that they are very similar and they should offer similar results when added to a stock-bond portfolio.

Although a correlation matrix is useful in that it shows the overall correlation between assets, it may be misleading since the relationship between assets is likely to vary substantially over time. Therefore we also run a dynamic conditional correlation (DCC) model of Engle (2002). We 
include an AR(1) term and plot the DCC GARCH(1,1) model in Figure 1., We can see from Figure 1 that the DCC between the two Bitcoin prices and the S\&P500 and bonds fluctuates quite considerably over time. There are periods where the correlation is positive (and as high as 0.4), but then there are other prolonged periods where the correlation is negative. Overall, Figure 1 suggests that there may be some diversification value in the inclusion of Bitcoin in a stock-bond portfolio.

\subsection{Out-of-sample benefits of Bitcoin}

In this section, we analyse the out-of-sample benefits of including Bitcoin in a stock-bond portfolio through a variety of asset allocation strategies with different level of risk aversion. Table 3 reports the results for the 52-week expanding window for both the mean and variance covariance matrix for the eight different asset strategies. We find that the inclusion of Bitcoin increases both the excess return and the standard deviation of our results. To determine whether the benefits of the increase in excess returns is wiped out by the increase in standard deviation, we examine numerous risk-adjusted return metrics. For each strategy, each risk-aversion and each performance metric, we find that the risk-adjusted measure increases each time Bitcoin is added to the stockbond portfolio. The mean Sharpe ratio for the stock-bond portfolio is 1.03 while the mean Sharpe ratio for the stock-bond-Bitcoin portfolio is 1.64, and the mean Omega ratio is 1.51 for the stockbond portfolio and 2.12 for the stock-bond-Bitcoin portfolio. However the biggest increase in our risk-adjusted measures comes from the Sortino ratio, where the average Sortino ratio increases from 1.62 to 3.57 indicating the downside risk when Bitcoin is included in the portfolio is very small. Investors with higher risk-aversions also benefit more from the inclusion of Bitcoin in their portfolio, which is not surprising given the high volatility in Bitcoin returns that are reported in Table 2. When comparing the different portfolio construction techniques, we find that adding Bitcoin to the portfolio adds, on average, most value (91.00\%) to the Minimum-Variance with Gens approach in regard to excess returns. Bitcoin adds least value to a Markowitz portfolio, but it adds, on average, $81.85 \%$ to the excess returns of the portfolio. Therefore our results are robust across all portfolio construction techniques employed.

As shown in Figure 2, Bitcoin experienced a huge surge in price during 2017 and there is the concern that our results will not be as strong during the first half of 2018 downturn. Therefore

\footnotetext{
${ }^{8}$ Other AR terms, GARCH models and alternative ADCC of Cappiello et al (2006) were examined but the DCCAR(1) GARCH(1,1)is preferred by the AIC statistic.

${ }^{9}$ For a detailed description of DCC models, see Engle (2002).
} 
in Figure 3, we report the time-series plot of the out-of-sample Sharpe ratio of the Markowitz model for portfolios excluding and including Bitcoin. Figure 3 shows that the inclusion of Bitcoin generates higher Sharpe ratios for each level of risk-aversion for the Markowitz model throughout our out-of-sample period indicating the stability of our results. Even during the downturn in the price of Bitcoin from January 2018 to June 2018, the portfolio including Bitcoin does consistently perform better than the traditional stock-bond portfolio indicating that even during this period, investors should look at including this alternative asset in their portfolio. ${ }^{10}$

Instead of employing a 52-week expanding window approach, Table 4 reports the 52 -week rolling window approach results where we find similar results in that adding Bitcoin to the stock-bond portfolio substantially increases the risk-adjusted measures for all 8 asset allocation strategies. ${ }^{11}$ Similar to the expanding window approach, the largest increase is risk-adjusted measures comes in the Sortino ratio, where we find that the average increase in the Sortino ratio from adding Bitcoin to a portfolio is $167.74 \%$, compared to $60.06 \%$ for the Sharpe ratio and $70.68 \%$ for the Omega ratio.

Initially, our analysis has employed the CoinDesk Bitcoin price, but as previously mentioned many other Bitcoin prices are available to investors through many other Bitcoin exchanges. Therefore to ensure our results are not the result of a specific Bitcoin price, we replace the CoinDesk price with the Bitstamp price, one of the most popular Bitcoin exchanges for U.S. investors. The results for the 52-week expanding window are reported in Table 5 and support our previous findings that including Bitcoin in our portfolio substantially increases the risk-adjusted returns, especially the Sortino ratio. The figures in Table 5 are broadly similar to the results of the expanding window in Table 3, and therefore indicate that no matter which Bitcoin price we choose, adding Bitcoin to a portfolio adds substantial value to investors.

So far, our analysis has been conducted exclusive of transaction costs. However with any investment strategy, transaction costs are very important since the value of adding Bitcoin to the portfolio may be eliminated when transaction costs are included making the strategy unprofitable.

\footnotetext{
${ }^{10}$ To conserve space, we do not present stability analysis of all portfolios however the results indicate that the inclusion of Bitcoin increases the risk-adjusted metrics consistently over time. These results are available from the corresponding author.

${ }^{11}$ To conserve space, we only report the risk-adjusted results from now on, but excess returns and standard deviations are available upon request from the corresponding author.
} 
The total transaction costs at time $t$ are subtracted from the portfolio returns when measuring the performance such that:

$$
\mathrm{TC}_{t}=\sum_{i=1}^{N} \mathrm{~T}_{i}\left(\left|\mathrm{x}_{i, t}-\mathrm{x}_{i, t-1}^{+}\right|\right),
$$

where $\mathrm{X}_{i, t-1}^{+}$denotes the weight of the $i^{\text {th }}$ asset at the end of the period $t-1$. We set the proportionate transactions cost $\left(T_{i}\right)$ of trading US equities at 50 bps (DeMiguel et al 2009) as well as 17 bps for the risk-free rate and bonds and $50 \mathrm{bps}$ for Bitcoin (Lintilhac and Tourin 2017). Table 6 reports the results of the 52-week expanding window estimation inclusive of transaction costs where again, Bitcoin adds value in that each risk-adjusted return measure is higher once Bitcoin has been added to the portfolio. Similar to the core results, the Minimum-Variance with Gens strategy has the largest increase in performance metric from adding Bitcoin (186.74\%) while the Markowitz with Gens has the smallest increase $(91.82 \%)$. This may be explained from the fact that minimumvariance portfolios with additional constraints (e.g. generalized constraints) for tackling further the negative effects of estimation errors in the input parameters adopt a more conservative stance towards risky assets like cryptocurrencies by under-weighting those assets in the portfolio construction process. This can often lead to a superior out-of-sample performance, especially during periods of high volatility when the negative effects of estimation errors when constructing optimal portfolios are more profound. Regarding choice of performance metrics, the average increase in metric from including Bitcoin in a portfolio is $98.19 \%$ for the Sharpe ratio, $62.55 \%$ for the Omega ratio and $187.04 \%$ for the Sortino ratio. Therefore, this suggests that even after the inclusive of transaction costs, investors should add Bitcoin to their portfolios.

\subsection{Portfolio Selection with Higher Moments}

Portfolio optimization techniques that are only based on the first two statistical moments (mean returns and the covariance matrix of returns) may have a weak out-of-sample performance when portfolio returns do not follow a normal distribution (Jondeau and Rockinger 2006; Cumming et al 2014). Hence we incorporate higher moments in the portfolio optimization process as a final robustness check. Specifically, we employ a constant relative risk aversion (CRRA) utility function such that: 


$$
U_{C R R A}(W)=\frac{1}{1-\lambda} W^{1-\lambda}, \quad \lambda>0, \lambda \neq 1,
$$

where $W$ denotes the end-of-period wealth. We express the expected CRRA utility function by considering a Taylor series expansion up to the $4^{\text {th }}$ order as follows:-

$$
E\left(U_{C R R A}(W)\right) \approx \frac{1}{1-\lambda} \bar{W}^{1-\lambda}-\frac{\lambda}{2} \bar{W}^{-(\lambda+1)} \sigma_{\mathrm{p}}^{2}+\frac{\lambda(\lambda+1)}{3 !} \bar{W}^{-(\lambda+2)} \mathrm{s}_{\mathrm{p}}^{3}-\frac{\lambda(\lambda+1)(\lambda+2)}{4 !} \bar{W}^{-(\lambda+3)} \mathrm{k}_{\mathrm{p}}^{4}
$$

where $\bar{W}=1+\mu_{\mathrm{p}} \cdot \mu_{\mathrm{p}}, \sigma_{\mathrm{p}}^{2}, \mathrm{~s}_{\mathrm{p}}^{3}$ and $\mathrm{k}_{\mathrm{p}}^{4}$ represent respectively the expected return, variance, skewness and kurtosis of the portfolio returns for a given vector of portfolio weights. ${ }^{12} \mathrm{We}$ maximise the expected CRRA utility function in terms of the vector of asset weights and the utility function is subject to the same constraints we employed in the main analysis (normalization of portfolio weights and short-selling constraints). Following Levy and Levy (2014), we also impose variance-based constraints (VBCs) as an alternative and intuitive method of decreasing further the negative effects of estimation risk in the optimal portfolio process. In particular, the variancebased constraints are described as follows:-

$$
\left|\mathrm{x}_{i}-\frac{1}{N}\right| \frac{\sigma_{i}}{\bar{\sigma}} \leq a, \quad \forall i
$$

where we set $\alpha$ to $10 \%$ and $\bar{\sigma}$ represents the average standard deviation of all asset classes used in each case of our analysis.

Table 7 presents the 52-week expanding window where we implement the higher moments method and this shows again, that Bitcoin offers substantial higher Sharpe, Omega and Sortino ratios to investors when Bitcoin is included in a stock-bond portfolio. Specially, Bitcoin adds on average $53.11 \%$ to the Sharpe ratio, $58.01 \%$ to the Omega ratio and $108.81 \%$ to the Sortino ratio for the general higher moments method, while the VBC method increases the Sharpe, Omega and Sortino ratios by $76.70 \%, 54.29 \%$ and $117.59 \%$ respectively. Therefore, our results are robust to including higher moments in the portfolio construction method as they also show that Bitcoin adds substantial value.

${ }^{12}$ See Platanakis et al (2017) for further details. 


\subsection{Portfolio Weights}

Our analysis has revealed that Bitcoin offers substantial portfolio benefits to a stock-bond portfolio which is not dependent on the asset allocation strategy or the risk-adjusted metric employed. To investigate further why the benefit is greater for certain asset allocation strategies, we also analyse the portfolio shares allocated to Bitcoin in different asset allocation strategies. Table 8 provides the average portfolio weight of Bitcoin and the standard deviation for all the optimization techniques used in this study. The standard deviation indicates how strongly the Bitcoin portfolio weight fluctuates over time, and we also report the maximum and minimum portfolio weight of Bitcoin. The standard deviation of Bitcoin portfolio weights is the highest in the Markowitz strategy, which is consistent with the well-known phenomenon of corner solutions and large portfolio reallocations (Best and Grauer, 1991; Bessler and Wolff, 2015). The maximum portfolio weight in Bitcoin is $99.99 \%$ for the Markowitz strategy with a risk aversion of 2, while the minimum portfolio weight in Bitcoin is $12.30 \%$ for the Markowitz strategy with a risk aversion of 10. We do find across most strategies that the higher the risk aversion of the investor, the lower the allocation to Bitcoin in the portfolio, indicating the relative riskiness of investing in Bitcoin. Therefore there is a wide-variation in the proportion of Bitcoin in each portfolio, depending on the asset allocation strategy and the risk aversion of the investor.

\subsection{Does Bitcoin add value beyond commodities?}

So far, our analysis has examined whether Bitcoin adds value to a stock-bond portfolio. However in the recent past commodities have been examined in great detail to determine whether they add value to an investors' portfolio (for recent positive evidence see Bessler and Wolff (2015) and Gao and Nardari (2018)). There is the concern that our results are just capturing the benefit already discovered in including commodities in a stock-bond portfolio. Therefore to alleviate this concern, we re-estimate our analysis but include a commodity index in our original stock-bond portfolio, and determine whether adding Bitcoin to the portfolio adds value for investors above and beyond that of a stock-bond-commodity portfolio. We choose the most popular and longest standing commodities index, namely the GSCI Commodity Index (Bessler and Wolff 2015), and the results from including it in our analysis are reported in Table 9. Consistent with our previous findings, Bitcoin clearly adds substantial value to the stock-bond-commodity portfolio with much higher Sharpe, Omega and Sortino ratios. In a number of cases, this new portfolio combining stocks, 
bonds, commodities and Bitcoin actually outperforms the stock-bond-Bitcoin portfolio on a riskadjusted basis. In Table 10 we report the portfolio weights of the assets in the stock-bondcommodity-Bitcoin portfolio, and shows that in all portfolios equities and Bitcoin have the largest share of the capital. In most cases Bitcoin has the largest weight indicating that in this setting we should allocate a substantial proportion of the capital to Bitcoin.

\subsection{Analysis with simulated data}

To further enhance the robustness and the generalization of our empirical findings so far, we also examine the out-of-sample diversification benefits of bitcoin when mixed with our benchmark (a stock-bond portfolio) by using simulated data. The main advantage of using simulated data is that the corresponding empirical findings are not driven by the various effects documented in the literature, such as anomalies, calendar effects and fat tails, amongst others. Using simulated data also decreases the effect of any subjective choices in the portfolio construction models such as the initial length of the estimation period for estimation the input parameters. More specifically, we fit a multivariate normal distribution to our data (equities, bonds, bitcoin and the risk-free rate) across the entire period (October 2011 to June 2018) and generate 2,000 observations for each asset class. Then we re-run our models in the same way as in the core part of our analysis and show that our main conclusions remain unchanged, e.g. including Bitcoin in our benchmark portfolio provides substantially higher risk-adjusted returns, as it can be seen in Table 11 below.

\subsection{Robustness with the CRIX Index}

So far, our analysis has focused on the portfolio benefits of the inclusion of only one cryptocurrency (Bitcoin) in a well-diversified portfolio. However, there are many altcoins available and they are becoming more and more popular. Therefore, we repeat our analysis and implement the broad, market-weighted cryptocurrency index CRIX, proposed by Timborn and Härdle (2018). ${ }^{13}$ This index provides an instrument which captures and displays the market movements of cryptocurrencies, not just Bitcoin, where we report our results in Table 12. Consistent with our previous findings for Bitcoin, we show that the inclusion of the CRIX index substantially increases the risk-adjusted returns across all eight asset allocation strategies indicating that our results are not Bitcoin specific but that an index of cryptocurrencies also substantially increases the out-ofsample risk-adjusted returns of a well-diversified portfolio.

\footnotetext{
13 The index can be sought from https://thecrix.de. We thank the reviewer for suggesting this additional analysis.
} 


\subsection{Loosening the short sale constraint}

Our previous analysis has implemented a short-selling constraint on Bitcoin, however Bitcoin futures were introduced by CBOE in December 2017 enabling the ability of investors to short Bitcoin in a safer manner. ${ }^{14}$ Therefore we re-estimate our analysis but remove the short-selling constraint where the results are presented in Table 13. We show that the inclusion of Bitcoin again substantially improves the risk-adjusted returns of our portfolio no matter which asset allocation strategy is implemented. Unsurprisingly, the risk-adjusted returns once short-selling is permitted are slightly higher than when short selling is constrained, indicating that investors can benefit more from short selling Bitcoin in their portfolio.

\section{Conclusions}

This paper investigates the potential out-of-sample benefits of adding Bitcoin to a stock-bond portfolio by analysing a variety of asset allocation strategies with three different levels of risk aversion. This is the first paper to examine the pure out-of-sample benefits of Bitcoin in a portfolio framework, and therefore adds substantially to the literature on Bitcoin as well as portfolio management.

Our empirical results suggest that the out-of-sample benefits of Bitcoin are consistent across portfolio construction techniques and different levels of risk aversion. Employing either an expanding window approach or a rolling window approach, we find that Bitcoin adds substantially to a stock-bond portfolio in terms of the Sharpe, Omega and Sortino ratios. Specifically, Bitcoin adds over $100 \%$ to the Sortino ratios of all portfolio construction techniques at all risk aversion levels. To test the robustness of our results, we replace the CoinDesk Bitcoin price with the Bitstamp Bitcoin price and our findings are consistent with the core results. Our results remain strong when short-selling is permitted, as well as when appropriate transaction costs are included. To alleviate the concern that our results may be attributed to the exclusion of commodities, we reestimate our models and determine whether Bitcoin can add value above and beyond a stockbond-commodity portfolio. We find that Bitcoin adds substantial value to an investor on a riskadjusted basis, and in each model a large proportion of the capital is allocated to Bitcoin. Finally,

\footnotetext{
14 Again, we thank the reviewer for pointing this out and suggesting this additional analysis.
} 
the robustness and generalization of our key empirical findings is enhanced further by using simulated data where the out-of-sample diversification benefits of bitcoin remain substantial.

No matter how appealing the findings of our results may be, caution must be stressed before implementing these portfolio techniques when computing optimal asset allocation decisions. Our analysis only employs a limited number of portfolio optimization strategies, and although we use an out-of-sample framework, our analysis is still based on the historical mean asset returns as return forecasts and the historical return variances and covariances. However historical returns can be poor estimates of future returns, especially when applied to Bitcoin given the large volatility in the price. Nevertheless, our analysis suggests that the inclusion of Bitcoin in portfolio allocation is beneficial to investors. 


\section{References}

Balcilar, M., Bouri, E., Gupta, R., Roubaud, D. (2017) Can volume predict Bitcoin returns and volatility? A quantiles-based approach. Economic Modelling, 64, 74-81.

Bariviera, A. F. (2017). The inefficiency of Bitcoin revisited: A dynamic approach. Economics Letters, $161,1-4$.

Baur, D. G., Hong, K., Lee, A. D. (2018). Bitcoin: Medium of Exchange or Speculative Asset? Journal of International Financial Markets, Institutions and Money, 54, 177-189.

Bessler, W., Wolff, D. (2015). Do commodities add value in multi-asset portfolios? An out-ofsample analysis for different investment strategies. Journal of Banking and Finance, 60 1-20.

Bessler, W., Opfer H., Wolff, D., (2017). Multi-Asset Portfolio Optimization and Out-of-Sample Performance: An Evaluation of Black-Litterman, Mean Variance and Naïve Diversification Approaches. The European Journal of Finance, 23, 1-30.

Black F., Litterman R. (1992). Global Portfolio Optimization. Financial Analysts Journal, 48, 28-43.

Board, J.L.G., Sutcliffe, C.M.S. (1994). Estimation Methods in Portfolio Selection and the Effectiveness of Short Sales Restrictions: UK Evidence. Management Science, 40, 516-534.

Bouri, E., Gupta, R., Tiwari, A., Roubaud, D. (2017a). Does Bitcoin hedge global uncertainty? Evidence from wavelet-based quantile-in-quantile regressions. Finance Research Letters, 23, 87-95.

Bouri, E., Molnár, P., Azzi, G., Roubaud, D., Hagfors, L. I. (2017b). On the hedge and safe haven properties of Bitcoin: Is it really more than a diversifier? Finance Research Letters, 20, 192198.

Brière, M., Oosterlinck, K., Szafarz, A. (2015). Virtual currency, tangible return: Portfolio diversification with bitcoin. Journal of Asset Management, 16, 365-373.

Cappiello, L., Engle, R. F., Sheppard, K. (2006). Asymmetric Dynamics in the Correlations of Global Equity and Bond Returns. Journal of Financial Econometrics, 4, 537-572.

Carroll, R., Conlon, T., Cotter, J. and Salvadro, E. (2017) Asset allocation with correlation: A composite trade-off, The European Journal of Operational Research, vol. 262, 1164-1180.

Cheah, E-T., Fry, J. (2015). Speculative bubbles in Bitcoin markets? An empirical investigation into the fundamental value of Bitcoin. Economics Letters, 130, 32-36.

Ciner, C., Gurdgiev, C., Lucey, B. M. (2013). Hedges and safe havens: An examination of stocks, bonds, gold, oil and exchange rates. International Review of Financial Analysis, 29, 202-211.

Conover, C.M., Jensen, G.R., Johnson, R.R., Mercer, J.M. (2010). Is Now the Time to Add Commodities to Your Portfolio? Journal of Investing, 19, 10-19.

Corbet, S., Lucey, B., Urquhart, A., Yarovaya, L. (2019). Cryptocurrencies as a Financial Asset: A systematic analysis. International Review of Financial Analysis, 62, 182-199

Cumming, D., Hass, L. H., Schweitzer, D. (2014). Strategic Asset Allocation and the Role of Alternative Investments. European Financial Management, 20, 521-547.

Daskalaki, C. and Skiadopoulos, G. (2011). Should Investors Include Commodities in their Portfolios After All? Journal of Banking and Finance, 35, 2606-2626.

DeMiguel, V., Garlappi, L., Uppal, R. (2009). Optimal versus naïve diversification: how inefficient is the $1 / \mathrm{N}$ portfolio strategy? Review of Financial Studies, 22, 1915-1953.

Dwyer, G. P. (2015). The economics of Bitcoin and similar private digital currencies. Journal of Financial Stability, 17, 81-91.

Dyhrberg, A. H. (2016). Hedging capabilities of bitcoin: Is it the virtual gold? Finance Research Letters, 16, 139-144.

Eisl, A., Gasser, S. M., Weinayer, K. (2015). Caveat Emptor: Does Bitcoin Improve Portfolio Diversification? Available at SSRN: https://ssrn.com/abstract=2408997

Engle, R. (2002). Dynamic Conditional Correlation. Journal of Business and Economic Statistics, 20, 339-350. 
Erb, C.B., Harvey, C.R. (2006). The Strategic and Tactical Value of Commodity Futures. Financial Analysts Journal, 62, 69-97.

Foley, S., Karlsen, J. R., Putninš, T. J. (2019). Sex, Drugs and Bitcoin: How Much Illegal Activity Is Financed through Cryptocurrencies? Review of Financial Studies, 32, 1798-1853.

Gandal, N., Hamrick, TJ., Moore, T., Oberman, T. (2018). Price manipulation in the Bitcoin ecosystem. Journal of Monetary Economics, 95, 86-96.

Gao, X., Nardari, F. (2018). Do Commodities Add Economic Value in Asset Allocation? New Evidence from Time-Varying Moments. Journal of Financial and Quantitative Analysis, 53, 365-393.

Gorton, G.B., Rouwenhorst, G.K. (2006). Facts and Fantasies about Commodity Futures. Financial Analysts Journal, vol. 62, 47-68.

Grobys, K., Sapkota, N. (2019). Cryptocurrencies and momentum. Economics Letters, 180, 6-10.

Guesmi, K., Saadi, S., Abid, I., Ftiti, Z. (2018). Portfolio diversification with virtual currency: Evidence from Bitcoin. International Review of Financial Analysis, forthcoming.

Hillier, D., Draper, P., Faff, R. (2006). Do precious metals shine? An investment perspective. Financial Analysts Journal, 62, 98-106.

Jondeau, E., Rockinger, M. (2006) Optimal Portfolio Allocation Under Higher Moments. European Financial Management, vol. 12, 29-55.

Jorion, P. (1986). Bayes-Stein Estimation for Portfolio Analysis. Journal of Financial and Quantitative Analysis, 21, 279-292.

Kajtazi, A., Moro, A. (2019). The role of bitcoin in well diversified portfolios: A comparative global study. International Review of Financial Analysis, 61, 143-157.

Kan, R., Zhou, G. (2007). Optimal Portfolio Choice with Parameter Uncertainty. Journal of Financial and Quantitative Analysis, 42, 621-656.

Katsiampa, P. (2017). Volatility estimation for Bitcoin: A comparison of GARCH models. Economics Letters, 158, 3-6.

Klein, T., Thu, H. P., Walther, T. (2018). Bitcoin is not the New Gold - A comparison of volatility, correlation, and portfolio performance. International Review of Financial Analysis, 59, 105-116.

Kolm, P.N., Tutuncu, R., abozzi, F.J. (2014). 60 Years of Portfolio Optimization: Practical Challenges and Current Trends. The European Journal of Operational Research, 234, 356-371.

Kristoufek, L. (2015). What are the main drivers of the Bitcoin price? Evidence from wavelet coherence analysis. PloS One, 10, e0123923.

Levy, M. and Roll, R. (2010) The market portfolio may be mean-variance efficient after all. The Review of Financial Studies, vol. 23, 2464-2491.

Levy, H., Levy, M. (2014). The Benefits of Differential Variance-Based Constraints in Portfolio Optimization. The European Journal of Operational Research, 234, 372-381.

Levy, H. and Simaan, Y. (2016) More Possessions, More Worry, The European Journal of Operational Research, vol. 255, 893-902.

Liu, Q., Tse, Y. and Zhang, L. (2018). Including Commodities in Asset Allocation in China, Quantitative Finance, 18, 1487-1499.

Lucey, B. M., Vigne, S. A., et al. (2018). Future directions in international financial integration research-a crowdsourced perspective. International Review of Financial Analysis, 55, 35-49.

Lintilhac, P. S., Tourin, A. (2017). Model-based pairs trading in the bitcoin markets. Quantitative Finance, 17, 703-716.

Makarov, I., Schoar, A. (2019). Trading and arbitrage in cryptocurrency markets. Journal of Financial Economics, forthcoming.

Markowitz, H. (1952). Portfolio Selection. Journal of Finance, 7, 77-91.

Markowitz, H. (2014). Mean-Variance Approximations to Expected Utility. The European Journal of Operational Research, 234, 346-355.

Meucci, A. (2010). The Black-Litterman Approach: Original Model and Extensions. The Encyclopedia of Quantitative Finance, Wiley. 
Nadarajah, S., Chu, J. (2017). On the inefficiency of Bitcoin. Economics Letters, 150, 6-9.

Nakamoto, S. (2008). Bitcoin: A Peer-to-Peer Electronic Cash System.

Oikonomou, I., Platanakis, E. and Sutcliffe, C. (2018). Socially Responsible Investment Portfolios: Does the Optimization Process Matter? The British Accounting Review, 50, 379-401.

Platanakis, E., Sakkas, A., Sutcliffe, C. (2019). Harmful Diversification: Evidence from Alternative Investments, The British Accounting Review, 51, 1-23.

Platanakis, E., Sutcliffe, C. (2017), Asset-Liability Modelling and Pension Schemes: The Application of Robust Optimization to USS. The European Journal of Finance, 23, 324-352.

Platanakis, E., Sutcliffe, C. and Urquhart, A. (2018). Optimal vs Naïve Diversification in Cryptocurrencies, Economics Letters, 171, 93-96.

Platanakis, E., Urquhart, A. (2019). Portfolio management with cryptocurrencies: The role of estimation risk. Economics Letters, 76-80.

Satchell, S., Scowcroft, A. (2000). A Demystification of the Black-Litterman Model: Managing Quantitative and Traditional Portfolio Construction. Journal of Asset Management, 2, 138150.

Shadwick, W.F., Keating, C. (2002). A Universal Performance Measure. Journal of Performance Measurement, 6, 59-84

Silva, T., Pinheiro, P.R., Poggi, M. (2017). A More Human-like Portfolio Optimization Approach. The European Journal of Operational Research, 256, 252-260.

Smetters, K., Zhang, X. (2014). A Sharper Ratio: A General Measure for Correctly Ranking NonNormal Investment Risks, Working paper, University of Pennsylvania.

Sharpe, W. F. (1966). Mutual fund performance. Journal of Business, 39, 119-138.

Shen, S., Urquhart, A., Wang, P. (2019). Does twitter predict Bitcoin? Economics Letters, 174, 118122.

Sortino, F.A., van der Meer, R. (1991). Downside Risk. Journal of Portfolio Management, 17, 27-31.

Trimborn, S., Härdle, W. K. (2018). CRIX an Index for cryptocurrencies. Journal of Empirical Finance, 49, 107-122.

Tu, J. (2010). Is Regime Switching in Stock Returns Important in Portfolio Decisions? Management Science, 56, 1198-1215.

Urquhart, A. (2016). The inefficiency of Bitcoin. Economics Letters, 148, 80-82.

Urquhart, A. (2017). Price clustering in Bitcoin. Economics Letters, 159, 145-148.

Urquhart, A., Zhang, H. (2019). Is Bitcoin a hedge of safe haven for currencies? An intraday analysis. International Review of Financial Analysis, 49-57.

Welch, I., Goyal, A. (2008). A Comprehensive Look at The Empirical Performance of Equity Premium Prediction. Review of Financial Studies, 21, 1455-1508.

Wu, C. Y., Pandey, V. K. (2014). The Value of Bitcoin in Enhancing the Efficiency of an Invetsor's Portfolio. Journal of Financial Planning, 27, 44-52.

Ziemba, W.T. and Mulvey, J.M. (1998) Worldwide Asset and Liability Modelling, Cambridge University Press. 
Table 1: This table presents the difference portfolio construction techniques employed in this study.

\begin{tabular}{|cc|}
\hline No. & Portfolio Optimization Technique \\
\hline 1 & Markowitz \\
2 & Markowitz with Gens \\
3 & Bayes-Stein \\
4 & Bayes-Stein with Gens \\
5 & Black-Litterman \\
6 & Minimum-Variance with Gens \\
7 & 1/n (with rebalancing) \\
8 & 3-Fund Portfolio Combination \\
\hline
\end{tabular}


Table 2: This table presents the descriptive statistics of the data employed in this study, as well as the Pearson correlation matrix between them. $* * *, * *$ and $*$ indicates significance at the $1 \%, 5 \%$ and $10 \%$ respectively for the Jarque-Bera test and the correlation matrix.

\begin{tabular}{cccccc}
\hline \multicolumn{2}{c}{ Panel A: Descriptive Statistics } & & & & \\
\hline & S\&P500 & U.S. Bond & Risk-free & CoinDesk & Bitstamp \\
\hline Mean & 0.0028 & -0.0002 & 0.0001 & 0.0319 & 0.0308 \\
St.Dev & 0.0165 & 0.0041 & 0.0001 & 0.1382 & 0.1350 \\
Max & 0.0742 & 0.0110 & 0.0004 & 0.6568 & 0.6559 \\
Min & -0.0666 & -0.0140 & 0.0000 & -0.4359 & -0.4446 \\
Skew & -0.5223 & -0.1672 & 1.6846 & 0.8301 & 0.8739 \\
Kurt & 2.6602 & 0.1865 & 1.5380 & 3.8104 & 3.9573 \\
Jarque-Bera & $11.4241 * * *$ & 2.0223 & $196.3143 * * *$ & $243.0123 * * *$ & $263.3743 * * *$ \\
\hline Panel B: Pearson Correlation Matrix & U.S. Bond & Risk-free & CoinDesk & Bitstamp \\
\hline \multicolumn{7}{c}{ S\&P500 } & -0.2349 & -0.0240 & 0.1412 & 0.1178 \\
S\&P 500 & & -0.0324 & -0.0379 & -0.0371 \\
U.S. Bond & $-0.2349 * * *$ & -0.0379 & -0.0446 & -0.0446 & -0.0410 \\
Risk-free & -0.0240 & -0.0371 & -0.0410 & $0.9757 * * *$ & $0.9757 * * *$ \\
CoinDesk & 0.1412 & 0.1178 & & & \\
Bitstamp & & & & & \\
\hline
\end{tabular}


Table 3: The results of the 52-week expanding window for both the mean and variance covariance matrix with no transaction costs and weekly rebalancing. 'Excess Return' and 'Std' denote the annualized mean excess portfolio returns and standard deviations while 'Sharpe Ratio', 'Omega Ratio', and 'Sortino Ratio' show the annualized Sharpe, Omega and Sortino ratios.

\begin{tabular}{|c|c|c|c|c|c|c|c|}
\hline \multirow[b]{2}{*}{ Method } & \multirow[b]{2}{*}{ Metric } & \multicolumn{2}{|c|}{$\lambda=2$} & \multicolumn{2}{|c|}{$\lambda=5$} & \multicolumn{2}{|c|}{$\lambda=10$} \\
\hline & & benchmark & (+Bitcoin) & benchmark & (+Bitcoin) & benchmark & (+Bitcoin) \\
\hline \multirow{5}{*}{ Markowitz } & Excess Return & 0.1345 & 1.4332 & 0.1339 & 0.7829 & 0.1197 & 0.4284 \\
\hline & Std & 0.1114 & 0.9289 & 0.1112 & 0.4714 & 0.1040 & 0.2456 \\
\hline & Sharpe Ratio & 1.1771 & 1.5393 & 1.1741 & 1.6535 & 1.1185 & 1.7305 \\
\hline & Omega Ratio & 1.5854 & 2.0393 & 1.5835 & 2.2886 & 1.5519 & 2.2358 \\
\hline & Sortino Ratio & 1.8790 & 3.3574 & 1.8727 & 3.7701 & 1.7576 & 3.8101 \\
\hline \multirow{5}{*}{ Markowitz with Gens } & Excess Return & 0.0971 & 1.0791 & 0.0970 & 0.7491 & 0.0948 & 0.4341 \\
\hline & Std & 0.0824 & 0.6805 & 0.0824 & 0.4577 & 0.0815 & 0.2454 \\
\hline & Sharpe Ratio & 1.1366 & 1.5807 & 1.1363 & 1.6291 & 1.1216 & 1.7548 \\
\hline & Omega Ratio & 1.5658 & 1.9891 & 1.5656 & 2.2612 & 1.5575 & 2.2707 \\
\hline & Sortino Ratio & 1.8014 & 3.3589 & 1.8007 & 3.7023 & 1.7709 & 3.9046 \\
\hline \multirow{5}{*}{ Bayes-Stein } & Excess Return & 0.1301 & 1.2422 & 0.1168 & 0.5938 & 0.0659 & 0.3125 \\
\hline & Std & 0.1096 & 0.8051 & 0.1044 & 0.3583 & 0.0727 & 0.1875 \\
\hline & Sharpe Ratio & 1.1559 & 1.5388 & 1.0859 & 1.6477 & 0.8609 & 1.6486 \\
\hline & Omega Ratio & 1.5755 & 2.1151 & 1.5411 & 2.2189 & 1.4261 & 2.1285 \\
\hline & Sortino Ratio & 1.8364 & 3.4276 & 1.6992 & 3.6138 & 1.2732 & 3.4677 \\
\hline \multirow{5}{*}{ Bayes-Stein with Gens } & Excess Return & 0.0949 & 1.0237 & 0.0914 & 0.5755 & 0.0676 & 0.3509 \\
\hline & Std & 0.0816 & 0.6554 & 0.0800 & 0.3551 & 0.0692 & 0.2032 \\
\hline & Sharpe Ratio & 1.1220 & 1.5567 & 1.1000 & 1.6113 & 0.9277 & 1.7106 \\
\hline & Omega Ratio & 1.5584 & 2.0052 & 1.5508 & 2.2145 & 1.4587 & 2.1265 \\
\hline & Sortino Ratio & 1.7727 & 3.3518 & 1.7340 & 3.5525 & 1.3989 & 3.6165 \\
\hline \multirow{5}{*}{ Black-Littermann } & Excess Return & 0.1121 & 0.6849 & 0.0745 & 0.5361 & 0.0600 & 0.4833 \\
\hline & Std & 0.0984 & 0.4021 & 0.0681 & 0.3169 & 0.0564 & 0.2885 \\
\hline & Sharpe Ratio & 1.1058 & 1.6946 & 1.0448 & 1.6808 & 1.0029 & 1.6635 \\
\hline & Omega Ratio & 1.5464 & 2.1336 & 1.5180 & 2.0922 & 1.4991 & 2.0666 \\
\hline & Sortino Ratio & 1.7295 & 3.7061 & 1.6229 & 3.6359 & 1.5561 & 3.5833 \\
\hline \multirow{5}{*}{ Min-Variance with Gens } & Excess Return & 0.0255 & 0.2829 & 0.0255 & 0.2829 & 0.0255 & 0.2829 \\
\hline & Std & 0.0341 & 0.1738 & 0.0341 & 0.1738 & 0.0341 & 0.1738 \\
\hline & Sharpe Ratio & 0.6478 & 1.6082 & 0.6478 & 1.6082 & 0.6478 & 1.6082 \\
\hline & Omega Ratio & 1.3243 & 1.9993 & 1.3243 & 1.9993 & 1.3243 & 1.9993 \\
\hline & Sortino Ratio & 0.9948 & 3.4490 & 0.9948 & 3.4490 & 0.9948 & 3.4490 \\
\hline \multirow{5}{*}{$1 / \mathbf{N}$} & Excess Return & 0.0596 & 0.5714 & 0.0596 & 0.5714 & 0.0596 & 0.5714 \\
\hline & Std & 0.0548 & 0.3448 & 0.0548 & 0.3448 & 0.0548 & 0.3448 \\
\hline & Sharpe Ratio & 1.0254 & 1.6471 & 1.0254 & 1.6471 & 1.0254 & 1.6471 \\
\hline & Omega Ratio & 1.5126 & 2.0393 & 1.5126 & 2.0393 & 1.5126 & 2.0393 \\
\hline & Sortino Ratio & 1.6038 & 3.5260 & 1.6038 & 3.5260 & 1.6038 & 3.5260 \\
\hline \multirow{5}{*}{ 3-Fund } & Excess Return & 0.1341 & 1.4291 & 0.1329 & 0.7744 & 0.1141 & 0.4221 \\
\hline & Std & 0.1111 & 0.9261 & 0.1106 & 0.4657 & 0.1003 & 0.2434 \\
\hline & Sharpe Ratio & 1.1765 & 1.5394 & 1.1712 & 1.6556 & 1.1032 & 1.7202 \\
\hline & Omega Ratio & 1.5850 & 2.0412 & 1.5817 & 2.2828 & 1.5452 & 2.2299 \\
\hline & Sortino Ratio & 1.8776 & 3.3584 & 1.8666 & 3.7663 & 1.7283 & 3.8016 \\
\hline
\end{tabular}


Table 4: The results of the 52-week rolling window for the mean with no transaction costs and weekly rebalancing. 'Sharpe Ratio' and 'Sortino Ratio' show the annualized Sharpe and Sortino ratios.

\begin{tabular}{|c|c|c|c|c|c|c|c|}
\hline \multirow[b]{2}{*}{ Method } & \multirow[b]{2}{*}{ Metric } & \multicolumn{2}{|c|}{$\lambda=2$} & \multicolumn{2}{|c|}{$\lambda=5$} & \multicolumn{2}{|c|}{$\lambda=10$} \\
\hline & & benchmark & (+Bitcoin) & benchmark & (+Bitcoin) & benchmark & (+Bitcoin) \\
\hline \multirow{3}{*}{ Markowitz } & Sharpe Ratio & 1.0223 & 1.4405 & 1.0696 & 1.3640 & 1.0199 & 1.4145 \\
\hline & Omega Ratio & 1.5083 & 2.0924 & 1.5417 & 2.1762 & 1.5236 & 2.1568 \\
\hline & Sortino Ratio & 1.5775 & 3.2073 & 1.6716 & 2.9914 & 1.5616 & 3.1124 \\
\hline \multirow{3}{*}{ Markowitz (Gens) } & Sharpe Ratio & 1.0369 & 1.5256 & 1.0674 & 1.4161 & 1.0690 & 1.5226 \\
\hline & Omega Ratio & 1.5163 & 2.0656 & 1.5388 & 2.1805 & 1.5419 & 2.1594 \\
\hline & Sortino Ratio & 1.5963 & 3.3920 & 1.6548 & 3.1695 & 1.6507 & 3.3046 \\
\hline \multirow{3}{*}{ Bayes-Stein } & Sharpe Ratio & 1.0036 & 1.2515 & 0.8133 & 1.2047 & 0.6270 & 1.2106 \\
\hline & Omega Ratio & 1.5304 & 2.1768 & 1.4356 & 2.1589 & 1.3297 & 2.0782 \\
\hline & Sortino Ratio & 1.5182 & 2.7896 & 1.2025 & 2.5503 & 0.9098 & 2.5610 \\
\hline \multirow{3}{*}{ Bayes-Stein (Gens) } & Sharpe Ratio & 1.0521 & 1.4065 & 0.9027 & 1.3166 & 0.7794 & 1.5100 \\
\hline & Omega Ratio & 1.5363 & 2.1334 & 1.4643 & 2.1249 & 1.3981 & 2.0535 \\
\hline & Sortino Ratio & 1.6126 & 3.1270 & 1.3537 & 2.7685 & 1.1495 & 3.1540 \\
\hline \multirow{3}{*}{ Black-Litterman } & Sharpe Ratio & 1.0883 & 1.5960 & 1.0411 & 1.6282 & 1.0004 & 1.6373 \\
\hline & Omega Ratio & 1.5446 & 2.1314 & 1.5174 & 2.0859 & 1.4970 & 2.0636 \\
\hline & Sortino Ratio & 1.6747 & 3.5323 & 1.5943 & 3.5499 & 1.5373 & 3.5445 \\
\hline \multirow{3}{*}{ Min-Variance (Gens) } & Sharpe Ratio & 0.6478 & 1.6082 & 0.6478 & 1.6082 & 0.6478 & 1.6082 \\
\hline & Omega Ratio & 1.3243 & 1.9993 & 1.3243 & 1.9993 & 1.3243 & 1.9993 \\
\hline & Sortino Ratio & 0.9948 & 3.4490 & 0.9948 & 3.4490 & 0.9948 & 3.4490 \\
\hline \multirow{3}{*}{$1 / N$} & Sharpe Ratio & 1.0254 & 1.6471 & 1.0254 & 1.6471 & 1.0254 & 1.6471 \\
\hline & Omega Ratio & 1.5126 & 2.0393 & 1.5126 & 2.0393 & 1.5126 & 2.0393 \\
\hline & Sortino Ratio & 1.6038 & 3.5260 & 1.6038 & 3.5260 & 1.6038 & 3.5260 \\
\hline \multirow{3}{*}{ 3-Fund } & Sharpe Ratio & 1.0290 & 1.4397 & 1.0790 & 1.3652 & 1.0067 & 1.4140 \\
\hline & Omega Ratio & 1.5145 & 2.0958 & 1.5486 & 2.1789 & 1.5192 & 2.1606 \\
\hline & Sortino Ratio & 1.5895 & 3.2042 & 1.6831 & 2.9863 & 1.5297 & 3.1126 \\
\hline
\end{tabular}


Table 5: The results of the 52-week expanding window for both the mean and variance covariance matrix with no transaction costs and weekly rebalancing for the Bitcoin index collected from Datastream. 'Sharpe Ratio' and 'Sortino Ratio' show the annualized Sharpe and Sortino ratios.

\begin{tabular}{|c|c|c|c|c|c|c|c|}
\hline \multirow[b]{2}{*}{ Method } & \multirow[b]{2}{*}{ Metric } & \multicolumn{2}{|c|}{$\lambda=2$} & \multicolumn{2}{|c|}{$\lambda=5$} & \multicolumn{2}{|c|}{$\lambda=10$} \\
\hline & & benchmark & (+Bitcoin) & benchmark & (+Bitcoin) & benchmark & (+Bitcoin) \\
\hline \multirow{3}{*}{ Markowitz } & Sharpe Ratio & 1.1771 & 1.5498 & 1.1741 & 1.6694 & 1.1185 & 1.7592 \\
\hline & Omega Ratio & 1.5854 & 2.0381 & 1.5835 & 2.3133 & 1.5519 & 2.2685 \\
\hline & Sortino Ratio & 1.8790 & 3.4258 & 1.8727 & 3.8473 & 1.7576 & 3.8694 \\
\hline \multirow{3}{*}{ Markowitz (Gens) } & Sharpe Ratio & 1.1366 & 1.5919 & 1.1363 & 1.6433 & 1.1216 & 1.7719 \\
\hline & Omega Ratio & 1.5658 & 1.9919 & 1.5656 & 2.2667 & 1.5575 & 2.3044 \\
\hline & Sortino Ratio & 1.8014 & 3.4203 & 1.8007 & 3.7636 & 1.7709 & 3.9585 \\
\hline \multirow{3}{*}{ Bayes-Stein } & Sharpe Ratio & 1.1559 & 1.5558 & 1.0859 & 1.6645 & 0.8609 & 1.6745 \\
\hline & Omega Ratio & 1.5755 & 2.1220 & 1.5411 & 2.2428 & 1.4261 & 2.1486 \\
\hline & Sortino Ratio & 1.8364 & 3.5027 & 1.6992 & 3.6639 & 1.2732 & 3.4955 \\
\hline \multirow{3}{*}{ Bayes-Stein (Gens) } & Sharpe Ratio & 1.1220 & 1.5682 & 1.1000 & 1.6244 & 0.9277 & 1.7425 \\
\hline & Omega Ratio & 1.5584 & 2.0085 & 1.5508 & 2.2338 & 1.4587 & 2.1616 \\
\hline & Sortino Ratio & 1.7727 & 3.4156 & 1.7340 & 3.6028 & 1.3989 & 3.6792 \\
\hline \multirow{3}{*}{ Black-Litterman } & Sharpe Ratio & 1.1058 & 1.7143 & 1.0448 & 1.6971 & 1.0029 & 1.6779 \\
\hline & Omega Ratio & 1.5464 & 2.1486 & 1.5180 & 2.1014 & 1.4991 & 2.0748 \\
\hline & Sortino Ratio & 1.7295 & 3.7839 & 1.6229 & 3.7036 & 1.5561 & 3.6467 \\
\hline \multirow{3}{*}{ Min-Variance (Gens) } & Sharpe Ratio & 0.6478 & 1.6205 & 0.6478 & 1.6205 & 0.6478 & 1.6205 \\
\hline & Omega Ratio & 1.3243 & 2.0068 & 1.3243 & 2.0068 & 1.3243 & 2.0068 \\
\hline & Sortino Ratio & 0.9948 & 3.5038 & 0.9948 & 3.5038 & 0.9948 & 3.5038 \\
\hline \multirow{3}{*}{$1 / N$} & Sharpe Ratio & 1.0254 & 1.6576 & 1.0254 & 1.6576 & 1.0254 & 1.6576 \\
\hline & Omega Ratio & 1.5126 & 2.0433 & 1.5126 & 2.0433 & 1.5126 & 2.0433 \\
\hline & Sortino Ratio & 1.6038 & 3.5822 & 1.6038 & 3.5822 & 1.6038 & 3.5822 \\
\hline \multirow{3}{*}{ 3-Fund } & Sharpe Ratio & 1.1765 & 1.5505 & 1.1712 & 1.6713 & 1.1032 & 1.7547 \\
\hline & Omega Ratio & 1.5850 & 2.0405 & 1.5817 & 2.3110 & 1.5452 & 2.2712 \\
\hline & Sortino Ratio & 1.8776 & 3.4294 & 1.8666 & 3.8491 & 1.7283 & 3.8632 \\
\hline
\end{tabular}


Table 6: The results of the 52-week expanding window for both the mean and variance covariance matrix with transaction costs and weekly rebalancing. 'Sharpe Ratio' and 'Sortino Ratio' show the annualized Sharpe and Sortino ratios.

\begin{tabular}{|c|c|c|c|c|c|c|c|}
\hline \multirow[b]{2}{*}{ Method } & \multirow[b]{2}{*}{ Metric } & \multicolumn{2}{|c|}{$\lambda=2$} & \multicolumn{2}{|c|}{$\lambda=5$} & \multicolumn{2}{|c|}{$\lambda=10$} \\
\hline & & benchmark & (+Bitcoin) & benchmark & (+Bitcoin) & benchmark & (+Bitcoin) \\
\hline \multirow{3}{*}{ Markowitz } & Sharpe Ratio & 1.1658 & 1.5353 & 1.1613 & 1.6328 & 1.0760 & 1.6941 \\
\hline & Omega Ratio & 1.5793 & 2.0352 & 1.5766 & 2.2627 & 1.5282 & 2.1957 \\
\hline & Sortino Ratio & 1.8551 & 3.3484 & 1.8461 & 3.7122 & 1.6830 & 3.7094 \\
\hline \multirow{3}{*}{ Markowitz (Gens) } & Sharpe Ratio & 1.1146 & 1.5681 & 1.1144 & 1.6111 & 1.0942 & 1.7248 \\
\hline & Omega Ratio & 1.5538 & 1.9773 & 1.5537 & 2.2389 & 1.5425 & 2.2361 \\
\hline & Sortino Ratio & 1.7590 & 3.3258 & 1.7586 & 3.6511 & 1.7197 & 3.8189 \\
\hline \multirow{3}{*}{ Bayes-Stein } & Sharpe Ratio & 1.1296 & 1.5291 & 1.0452 & 1.6252 & 0.7710 & 1.6025 \\
\hline & Omega Ratio & 1.5610 & 2.1043 & 1.5178 & 2.1923 & 1.3775 & 2.0824 \\
\hline & Sortino Ratio & 1.7890 & 3.4039 & 1.6314 & 3.5511 & 1.1331 & 3.3518 \\
\hline \multirow{3}{*}{ Bayes-Stein (Gens) } & Sharpe Ratio & 1.0895 & 1.5453 & 1.0700 & 1.5914 & 0.8603 & 1.6684 \\
\hline & Omega Ratio & 1.5406 & 1.9941 & 1.5336 & 2.1910 & 1.4218 & 2.0853 \\
\hline & Sortino Ratio & 1.7132 & 3.3213 & 1.6825 & 3.4980 & 1.2907 & 3.5078 \\
\hline \multirow{3}{*}{ Black-Litterman } & Sharpe Ratio & 1.0646 & 1.6652 & 1.0214 & 1.6530 & 0.9796 & 1.6360 \\
\hline & Omega Ratio & 1.5232 & 2.1042 & 1.5053 & 2.0653 & 1.4868 & 2.0404 \\
\hline & Sortino Ratio & 1.6569 & 3.6257 & 1.5802 & 3.5601 & 1.5135 & 3.5083 \\
\hline \multirow{3}{*}{ Min-Variance (Gens) } & Sharpe Ratio & 0.6080 & 1.5767 & 0.6080 & 1.5767 & 0.6080 & 1.5767 \\
\hline & Omega Ratio & 1.3051 & 1.9705 & 1.3051 & 1.9705 & 1.3051 & 1.9705 \\
\hline & Sortino Ratio & 0.9286 & 3.3654 & 0.9286 & 3.3654 & 0.9286 & 3.3654 \\
\hline \multirow{3}{*}{$1 / N$} & Sharpe Ratio & 0.9916 & 1.6209 & 0.9916 & 1.6209 & 0.9916 & 1.6209 \\
\hline & Omega Ratio & 1.4945 & 2.0148 & 1.4945 & 2.0148 & 1.4945 & 2.0148 \\
\hline & Sortino Ratio & 1.5424 & 3.4561 & 1.5424 & 3.4561 & 1.5424 & 3.4561 \\
\hline \multirow{3}{*}{ 3-Fund } & Sharpe Ratio & 1.1648 & 1.5352 & 1.1569 & 1.6346 & 1.0417 & 1.6749 \\
\hline & Omega Ratio & 1.5787 & 2.0369 & 1.5740 & 2.2567 & 1.5109 & 2.1810 \\
\hline & Sortino Ratio & 1.8532 & 3.3489 & 1.8374 & 3.7076 & 1.6228 & 3.6799 \\
\hline
\end{tabular}


Table 7: The results of the 52-week expanding window for both the mean and variance covariance matrix with transaction costs and weekly rebalancing for the higher moments construction method, as well as the higher moments construction method with variance-based constraints (VBCs) of Levy and Levy (2014), where alpha is 10\%.'Sharpe Ratio' and 'Sortino Ratio' show the annualized Sharpe and Sortino ratios.

\begin{tabular}{cccccccc}
\hline & & \multicolumn{2}{c}{$\boldsymbol{\lambda = 2}$} & \multicolumn{2}{c}{$\boldsymbol{\lambda}=\mathbf{5}$} & \multicolumn{2}{c}{$\boldsymbol{\lambda}=\mathbf{1 0}$} \\
\hline \multirow{2}{*}{ Method } & Metric & benchmark & (+Bitcoin) & benchmark & (+Bitcoin) & benchmark & (+Bitcoin) \\
\hline \multirow{2}{*}{ Higher Moments } & Sharpe Ratio & 1.1768 & 1.5333 & 1.1717 & 1.6170 & 1.1055 & 1.6900 \\
& Omega Ratio & 1.5852 & 2.0161 & 1.5819 & 2.2457 & 1.5464 & 2.2031 \\
& Sortino Ratio & 1.8783 & 3.3209 & 1.8672 & 3.5737 & 1.7300 & 3.6301 \\
\hline \multirow{3}{*}{ Higher Moments (VBCs) } & Sharpe Ratio & 1.0645 & 1.7218 & 1.0643 & 1.7017 & 1.0605 & 1.6977 \\
& Omega Ratio & 1.5316 & 2.0850 & 1.5315 & 2.0939 & 1.5293 & 2.0895 \\
& Sortino Ratio & 1.6708 & 3.6929 & 1.6704 & 3.6880 & 1.6629 & 3.6190 \\
\hline
\end{tabular}


Table 8: The portfolio weights of the out-of-sample optimized portfolios. 'Mean' denotes the average portfolio weight while 'Std' denotes the associated standard deviation of the portfolio weight. 'Maximum' refers to the maximum portfolio share allocated to that asset while 'minimum' refers the minimum portfolio share allocated to that asset. All figures are reported in percentages.

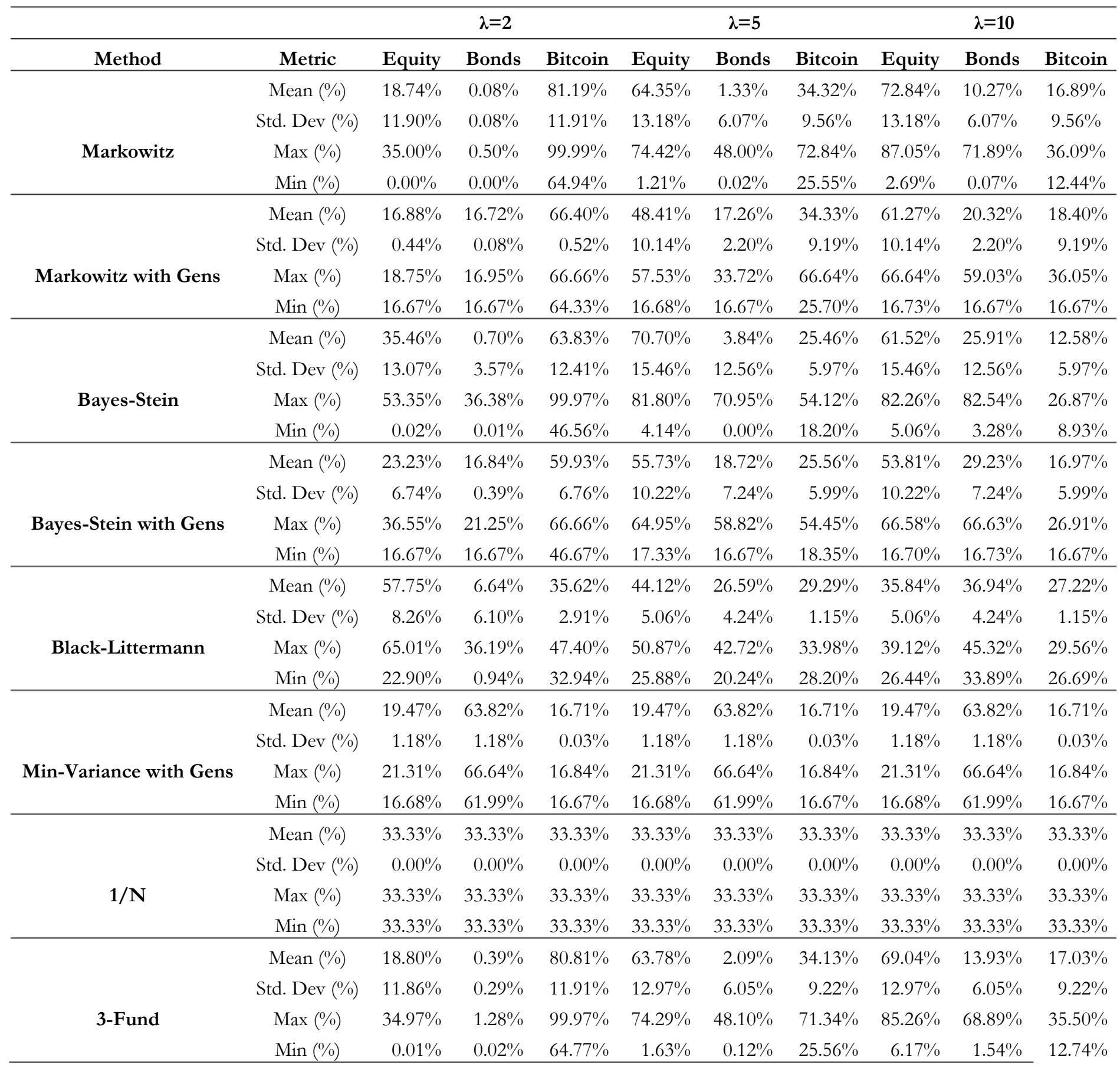


Table 9: The results of the 52-week expanding window for both the mean and variance covariance matrix with commodities added to the original stock-bond portfolio. 'Sharpe Ratio' and 'Sortino Ratio' show the annualized Sharpe and Sortino ratios.

\begin{tabular}{|c|c|c|c|c|c|c|c|}
\hline \multirow[b]{2}{*}{ Method } & \multirow[b]{2}{*}{ Metric } & \multicolumn{2}{|c|}{$\lambda=2$} & \multicolumn{2}{|c|}{$\lambda=5$} & \multicolumn{2}{|c|}{$\lambda=10$} \\
\hline & & benchmark & (+Bitcoin) & benchmark & (+Bitcoin) & benchmark & (+Bitcoin) \\
\hline \multirow{3}{*}{ Markowitz } & Sharpe Ratio & 1.1759 & 1.5389 & 1.1740 & 1.6537 & 1.1159 & 1.7299 \\
\hline & Omega Ratio & 1.5846 & 2.0392 & 1.5836 & 2.2889 & 1.5516 & 2.2353 \\
\hline & Sortino Ratio & 1.8765 & 3.3566 & 1.8732 & 3.7705 & 1.7517 & 3.8053 \\
\hline \multirow{3}{*}{ Markowitz (Gens) } & Sharpe Ratio & 0.7776 & 1.5579 & 0.7772 & 1.5843 & 0.7543 & 1.6321 \\
\hline & Omega Ratio & 1.3614 & 1.9671 & 1.3612 & 2.1870 & 1.3502 & 2.1574 \\
\hline & Sortino Ratio & 1.1973 & 3.2852 & 1.1967 & 3.5494 & 1.1548 & 3.5572 \\
\hline \multirow{3}{*}{ Bayes-Stein } & Sharpe Ratio & 1.1502 & 1.5444 & 1.1164 & 1.6550 & 0.8850 & 1.6528 \\
\hline & Omega Ratio & 1.5712 & 2.1044 & 1.5605 & 2.2015 & 1.4369 & 2.1035 \\
\hline & Sortino Ratio & 1.8266 & 3.4230 & 1.7676 & 3.6087 & 1.3200 & 3.4334 \\
\hline \multirow{3}{*}{ Bayes-Stein (Gens) } & Sharpe Ratio & 0.7537 & 1.5398 & 0.7361 & 1.5566 & 0.5670 & 1.5753 \\
\hline & Omega Ratio & 1.3500 & 1.9674 & 1.3447 & 2.1260 & 1.2642 & 2.0218 \\
\hline & Sortino Ratio & 1.1558 & 3.2567 & 1.1285 & 3.3535 & 0.8413 & 3.2194 \\
\hline \multirow{3}{*}{ Black-Litterman } & Sharpe Ratio & 1.0899 & 1.7119 & 0.8561 & 1.6786 & 0.5543 & 1.6279 \\
\hline & Omega Ratio & 1.5333 & 2.1434 & 1.4087 & 2.0767 & 1.2578 & 2.0191 \\
\hline & Sortino Ratio & 1.7114 & 3.7379 & 1.3065 & 3.5850 & 0.8384 & 3.4269 \\
\hline \multirow{3}{*}{ Min-Variance (Gens) } & Sharpe Ratio & -0.0859 & 1.4452 & -0.0859 & 1.4452 & -0.0859 & 1.4452 \\
\hline & Omega Ratio & 0.9945 & 1.8520 & 0.9945 & 1.8520 & 0.9945 & 1.8520 \\
\hline & Sortino Ratio & -0.1324 & 2.9516 & -0.1324 & 2.9516 & -0.1324 & 2.9516 \\
\hline \multirow{3}{*}{$1 / N$} & Sharpe Ratio & 0.0857 & 1.5208 & 0.0857 & 1.5208 & 0.0857 & 1.5208 \\
\hline & Omega Ratio & 1.0496 & 1.8993 & 1.0496 & 1.8993 & 1.0496 & 1.8993 \\
\hline & Sortino Ratio & 0.1332 & 3.1210 & 0.1332 & 3.1210 & 0.1332 & 3.1210 \\
\hline \multirow{3}{*}{ 3-Fund } & Sharpe Ratio & 1.1742 & 1.5368 & 1.1711 & 1.6549 & 1.1113 & 1.7246 \\
\hline & Omega Ratio & 1.5836 & 2.0384 & 1.5819 & 2.2827 & 1.5489 & 2.2296 \\
\hline & Sortino Ratio & 1.8734 & 3.3511 & 1.8674 & 3.7651 & 1.7428 & 3.7921 \\
\hline
\end{tabular}


Table 10: The portfolio weights of the out-of-sample optimized portfolios when commodities is included. 'Mean' denotes the average portfolio weight while 'Std' denotes the associated standard deviation of the portfolio weight. 'Maximum' refers to the maximum portfolio share allocated to that asset while 'minimum' refers the minimum portfolio share allocated to that asset. All figures are reported in percentages.

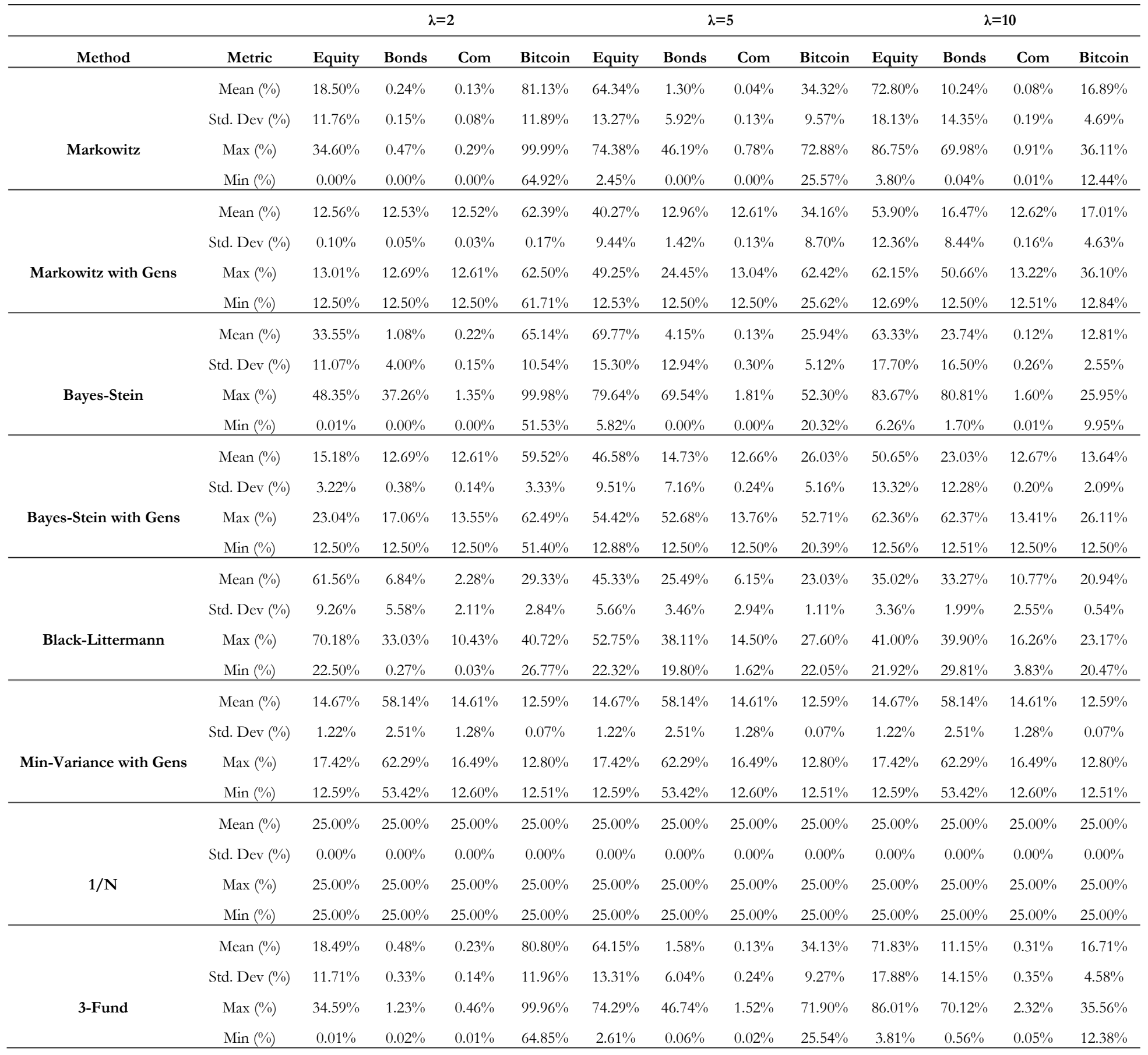


Table 11: The results of the 52-week expanding window for both the mean and variance covariance matrix with no transaction costs and weekly rebalancing by using 2,000 simulated data. 'Sharpe Ratio' and 'Sortino Ratio' show the annualized Sharpe and Sortino ratios.

\begin{tabular}{|c|c|c|c|c|c|c|c|}
\hline \multirow[b]{2}{*}{ Method } & \multirow[b]{2}{*}{ Metric } & \multicolumn{2}{|c|}{$\lambda=2$} & \multicolumn{2}{|c|}{$\lambda=5$} & \multicolumn{2}{|c|}{$\lambda=10$} \\
\hline & & benchmark & (+Bitcoin) & benchmark & (+Bitcoin) & benchmark & (+Bitcoin) \\
\hline \multirow{3}{*}{ Markowitz } & Sharpe Ratio & 1.3309 & 1.5992 & 1.3307 & 1.7583 & 1.3220 & 1.9003 \\
\hline & Omega Ratio & 1.5973 & 1.7505 & 1.5972 & 1.8670 & 1.5924 & 1.9627 \\
\hline & Sortino Ratio & 2.5611 & 3.1411 & 2.5607 & 3.4430 & 2.5379 & 3.7439 \\
\hline \multirow{3}{*}{ Markowitz (Gens) } & Sharpe Ratio & 1.3206 & 1.6223 & 1.3206 & 1.7135 & 1.3191 & 1.8786 \\
\hline & Omega Ratio & 1.5966 & 1.7618 & 1.5965 & 1.8361 & 1.5958 & 1.9406 \\
\hline & Sortino Ratio & 2.5456 & 3.2128 & 2.5455 & 3.3464 & 2.5419 & 3.7216 \\
\hline \multirow{3}{*}{ Bayes-Stein } & Sharpe Ratio & 1.3246 & 1.6048 & 1.3193 & 1.7963 & 1.2788 & 1.9039 \\
\hline & Omega Ratio & 1.5938 & 1.7543 & 1.5913 & 1.8829 & 1.5730 & 1.9603 \\
\hline & Sortino Ratio & 2.5446 & 3.1453 & 2.5287 & 3.5412 & 2.4248 & 3.7595 \\
\hline \multirow{3}{*}{ Bayes-Stein (Gens) } & Sharpe Ratio & 1.3159 & 1.6182 & 1.3134 & 1.7477 & 1.2999 & 1.8959 \\
\hline & Omega Ratio & 1.5940 & 1.7598 & 1.5926 & 1.8523 & 1.5860 & 1.9466 \\
\hline & Sortino Ratio & 2.5337 & 3.2002 & 2.5254 & 3.4368 & 2.4898 & 3.7797 \\
\hline \multirow{3}{*}{ Black-Litterman } & Sharpe Ratio & 1.3107 & 1.7759 & 1.2925 & 1.7604 & 1.2694 & 1.7371 \\
\hline & Omega Ratio & 1.5872 & 1.8639 & 1.5842 & 1.8540 & 1.5771 & 1.8388 \\
\hline & Sortino Ratio & 2.5127 & 3.5271 & 2.4847 & 3.4997 & 2.4419 & 3.4518 \\
\hline \multirow{3}{*}{ Min-Variance (Gens) } & Sharpe Ratio & 1.0358 & 1.6981 & 1.0358 & 1.6981 & 1.0358 & 1.6981 \\
\hline & Omega Ratio & 1.4714 & 1.8170 & 1.4714 & 1.8170 & 1.4714 & 1.8170 \\
\hline & Sortino Ratio & 1.9628 & 3.3653 & 1.9628 & 3.3653 & 1.9628 & 3.3653 \\
\hline \multirow{3}{*}{$1 / \mathrm{N}$} & Sharpe Ratio & 1.2682 & 1.7039 & 1.2682 & 1.7039 & 1.2682 & 1.7039 \\
\hline & Omega Ratio & 1.5781 & 1.8159 & 1.5781 & 1.8159 & 1.5781 & 1.8159 \\
\hline & Sortino Ratio & 2.4428 & 3.3852 & 2.4428 & 3.3852 & 2.4428 & 3.3852 \\
\hline \multirow{3}{*}{ 3-Fund } & Sharpe Ratio & 1.3307 & 1.6001 & 1.3302 & 1.7596 & 1.3189 & 1.8923 \\
\hline & Omega Ratio & 1.5972 & 1.7510 & 1.5970 & 1.8670 & 1.5915 & 1.9561 \\
\hline & Sortino Ratio & 2.5606 & 3.1438 & 2.5595 & 3.4495 & 2.5299 & 3.7283 \\
\hline
\end{tabular}


Table 12: The results of the 52-week expanding window for the CRIX index both the mean and variance covariance matrix with no transaction costs and weekly rebalancing. 'Sharpe Ratio' and 'Sortino Ratio' show the annualized Sharpe and Sortino ratios.

\begin{tabular}{|c|c|c|c|c|c|c|c|}
\hline \multirow[b]{2}{*}{ Method } & \multirow[b]{2}{*}{ Metric } & \multicolumn{2}{|c|}{$\lambda=2$} & \multicolumn{2}{|c|}{$\lambda=5$} & \multicolumn{2}{|c|}{$\lambda=10$} \\
\hline & & benchmark & (+CRIX) & benchmark & (+CRIX) & benchmark & (+CRIX) \\
\hline \multirow{3}{*}{ Markowitz } & Sharpe Ratio & 0.8556 & 1.4091 & 0.7371 & 1.4652 & 0.6352 & 1.4847 \\
\hline & Omega Ratio & 1.4348 & 1.8937 & 1.3787 & 1.8914 & 1.3568 & 1.9195 \\
\hline & Sortino Ratio & 1.2443 & 2.8324 & 1.0258 & 2.8351 & 0.8514 & 2.7187 \\
\hline \multirow{3}{*}{ Markowitz (Gens) } & Sharpe Ratio & 0.8335 & 1.6062 & 0.7533 & 1.6368 & 0.6744 & 1.8510 \\
\hline & Omega Ratio & 1.4344 & 2.0014 & 1.3936 & 1.9897 & 1.3727 & 2.0825 \\
\hline & Sortino Ratio & 1.2058 & 3.3084 & 1.0551 & 3.2112 & 0.9102 & 3.4798 \\
\hline \multirow{3}{*}{ Bayes-Stein } & Sharpe Ratio & 0.8053 & 1.1787 & 0.5441 & 1.2808 & 0.3430 & 1.2273 \\
\hline & Omega Ratio & 1.4626 & 1.8130 & 1.3462 & 1.8902 & 1.2399 & 1.8225 \\
\hline & Sortino Ratio & 1.1304 & 2.2152 & 0.7211 & 2.3601 & 0.4484 & 2.1012 \\
\hline \multirow{3}{*}{ Bayes-Stein (Gens) } & Sharpe Ratio & 0.8069 & 1.4087 & 0.7432 & 1.6506 & 0.5254 & 1.9043 \\
\hline & Omega Ratio & 1.4481 & 1.8980 & 1.4345 & 2.0167 & 1.3207 & 2.1418 \\
\hline & Sortino Ratio & 1.1244 & 2.7597 & 1.0238 & 3.0843 & 0.7080 & 3.5792 \\
\hline \multirow{3}{*}{ Black-Litterman } & Sharpe Ratio & 0.7805 & 1.8539 & 0.7556 & 1.9138 & 0.7247 & 1.9326 \\
\hline & Omega Ratio & 1.4122 & 2.1046 & 1.4130 & 2.1327 & 1.4032 & 2.1396 \\
\hline & Sortino Ratio & 1.0873 & 3.6685 & 1.0577 & 3.7961 & 1.0189 & 3.8502 \\
\hline \multirow{3}{*}{ Min-Variance (Gens) } & Sharpe Ratio & 0.4487 & 1.9239 & 0.4487 & 1.9239 & 0.4487 & 1.9239 \\
\hline & Omega Ratio & 1.2823 & 2.1251 & 1.2823 & 2.1251 & 1.2823 & 2.1251 \\
\hline & Sortino Ratio & 0.6330 & 3.8071 & 0.6330 & 3.8071 & 0.6330 & 3.8071 \\
\hline \multirow{3}{*}{$1 / N$} & Sharpe Ratio & 0.7857 & 1.9640 & 0.7857 & 1.9640 & 0.7857 & 1.9640 \\
\hline & Omega Ratio & 1.4336 & 2.1541 & 1.4336 & 2.1541 & 1.4336 & 2.1541 \\
\hline & Sortino Ratio & 1.1318 & 3.9578 & 1.1318 & 3.9578 & 1.1318 & 3.9578 \\
\hline \multirow{3}{*}{ 3-Fund } & Sharpe Ratio & 0.8463 & 1.4118 & 0.7344 & 1.4667 & 0.5894 & 1.4966 \\
\hline & Omega Ratio & 1.4297 & 1.8988 & 1.3822 & 1.8994 & 1.3361 & 1.9364 \\
\hline & Sortino Ratio & 1.2210 & 2.8426 & 1.0141 & 2.8376 & 0.7828 & 2.7491 \\
\hline
\end{tabular}


Table 13: The results of the 52-week expanding window for both the mean and variance covariance matrix with no transaction costs, weekly rebalancing and by allowing for short-selling. 'Sharpe Ratio' and 'Sortino Ratio' show the annualized Sharpe and Sortino ratios.

\begin{tabular}{|c|c|c|c|c|c|c|c|}
\hline \multirow[b]{2}{*}{ Method } & \multirow[b]{2}{*}{ Metric } & \multicolumn{2}{|c|}{$\lambda=2$} & \multicolumn{2}{|c|}{$\lambda=5$} & \multicolumn{2}{|c|}{$\lambda=10$} \\
\hline & & benchmark & (+Bitcoin) & benchmark & (+Bitcoin) & benchmark & (+Bitcoin) \\
\hline \multirow{3}{*}{ Markowitz } & Sharpe Ratio & 1.0888 & 1.7316 & 1.0747 & 1.7255 & 1.0398 & 1.7110 \\
\hline & Omega Ratio & 1.5334 & 2.2156 & 1.5284 & 2.2132 & 1.5114 & 2.2005 \\
\hline & Sortino Ratio & 1.6840 & 3.7525 & 1.6546 & 3.7415 & 1.5924 & 3.7089 \\
\hline \multirow{3}{*}{ Markowitz (Gens) } & Sharpe Ratio & 1.1366 & 1.5807 & 1.1363 & 1.6291 & 1.1216 & 1.7548 \\
\hline & Omega Ratio & 1.5658 & 1.9891 & 1.5656 & 2.2612 & 1.5575 & 2.2707 \\
\hline & Sortino Ratio & 1.8014 & 3.3589 & 1.8007 & 3.7023 & 1.7709 & 3.9046 \\
\hline \multirow{3}{*}{ Bayes-Stein } & Sharpe Ratio & 0.9562 & 1.6779 & 0.9259 & 1.6687 & 0.8535 & 1.6466 \\
\hline & Omega Ratio & 1.4704 & 2.1543 & 1.4569 & 2.1490 & 1.4225 & 2.1255 \\
\hline & Sortino Ratio & 1.4263 & 3.5239 & 1.3731 & 3.5058 & 1.2596 & 3.4559 \\
\hline \multirow{3}{*}{ Bayes-Stein (Gens) } & Sharpe Ratio & 1.1220 & 1.5567 & 1.1000 & 1.6113 & 0.9277 & 1.7106 \\
\hline & Omega Ratio & 1.5584 & 2.0052 & 1.5508 & 2.2145 & 1.4587 & 2.1265 \\
\hline & Sortino Ratio & 1.7727 & 3.3518 & 1.7340 & 3.5525 & 1.3989 & 3.6165 \\
\hline \multirow{3}{*}{ Black-Litterman } & Sharpe Ratio & 1.0863 & 1.7103 & 1.0440 & 1.6807 & 1.0036 & 1.6633 \\
\hline & Omega Ratio & 1.5346 & 2.1336 & 1.5174 & 2.0920 & 1.4994 & 2.0664 \\
\hline & Sortino Ratio & 1.6867 & 3.7311 & 1.6200 & 3.6356 & 1.5571 & 3.5827 \\
\hline \multirow{3}{*}{ Min-Variance (Gens) } & Sharpe Ratio & 0.6478 & 1.6082 & 0.6478 & 1.6082 & 0.6478 & 1.6082 \\
\hline & Omega Ratio & 1.3243 & 1.9993 & 1.3243 & 1.9993 & 1.3243 & 1.9993 \\
\hline & Sortino Ratio & 0.9948 & 3.4490 & 0.9948 & 3.4490 & 0.9948 & 3.4490 \\
\hline \multirow{3}{*}{$1 / \mathbf{N}$} & Sharpe Ratio & 1.0254 & 1.6471 & 1.0254 & 1.6471 & 1.0254 & 1.6471 \\
\hline & Omega Ratio & 1.5126 & 2.0393 & 1.5126 & 2.0393 & 1.5126 & 2.0393 \\
\hline & Sortino Ratio & 1.6038 & 3.5260 & 1.6038 & 3.5260 & 1.6038 & 3.5260 \\
\hline \multirow{3}{*}{ 3-Fund } & Sharpe Ratio & 1.0892 & 1.7324 & 1.0747 & 1.7249 & 1.0389 & 1.7093 \\
\hline & Omega Ratio & 1.5337 & 2.2168 & 1.5284 & 2.2139 & 1.5109 & 2.1967 \\
\hline & Sortino Ratio & 1.6849 & 3.7552 & 1.6546 & 3.7423 & 1.5906 & 3.6968 \\
\hline
\end{tabular}


Figure 1: The dynamic conditional correlations of an $\mathrm{AR}(1)-\mathrm{GARCH}(1,1)$ model between the S\&P500 and two Bitcoin prices, as well as the U.S. bonds and the two Bitcoin prices.

$\operatorname{DCC}-A R(1)-G A R C H(1,1)$

0.5

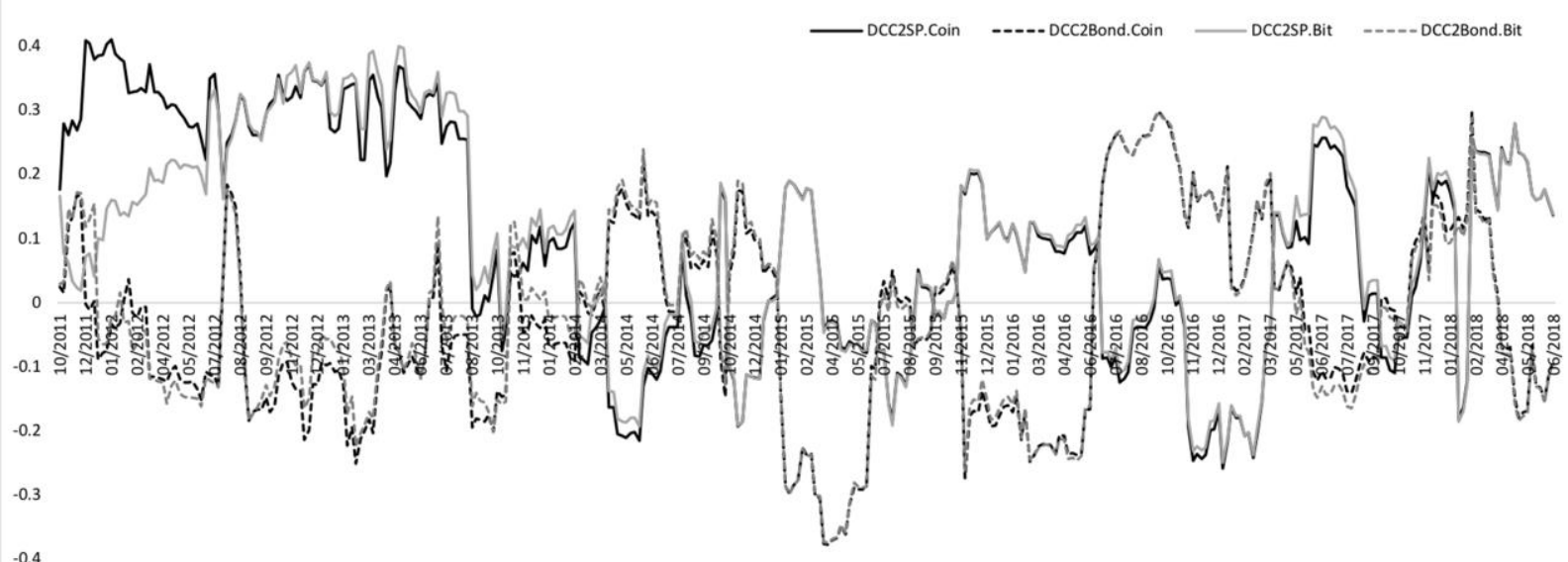


Figure 2: Time-series plot of the price of Bitstamp.

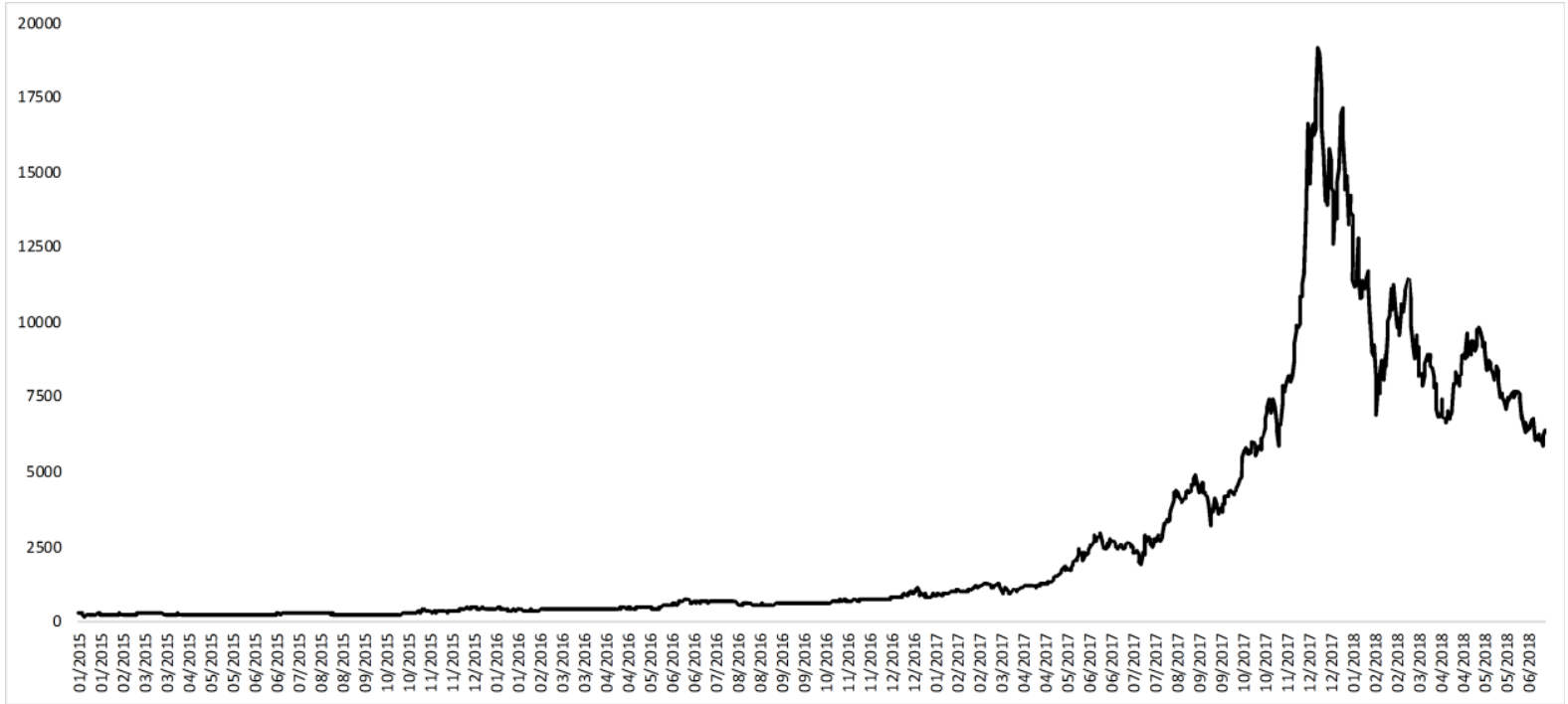


Figure 3: The out-of-sample Sharpe ratios for the 52-week expanding window for the traditional stock-bond portfolio and the traditional portfolio including Bitcoin for the Markowitz model.
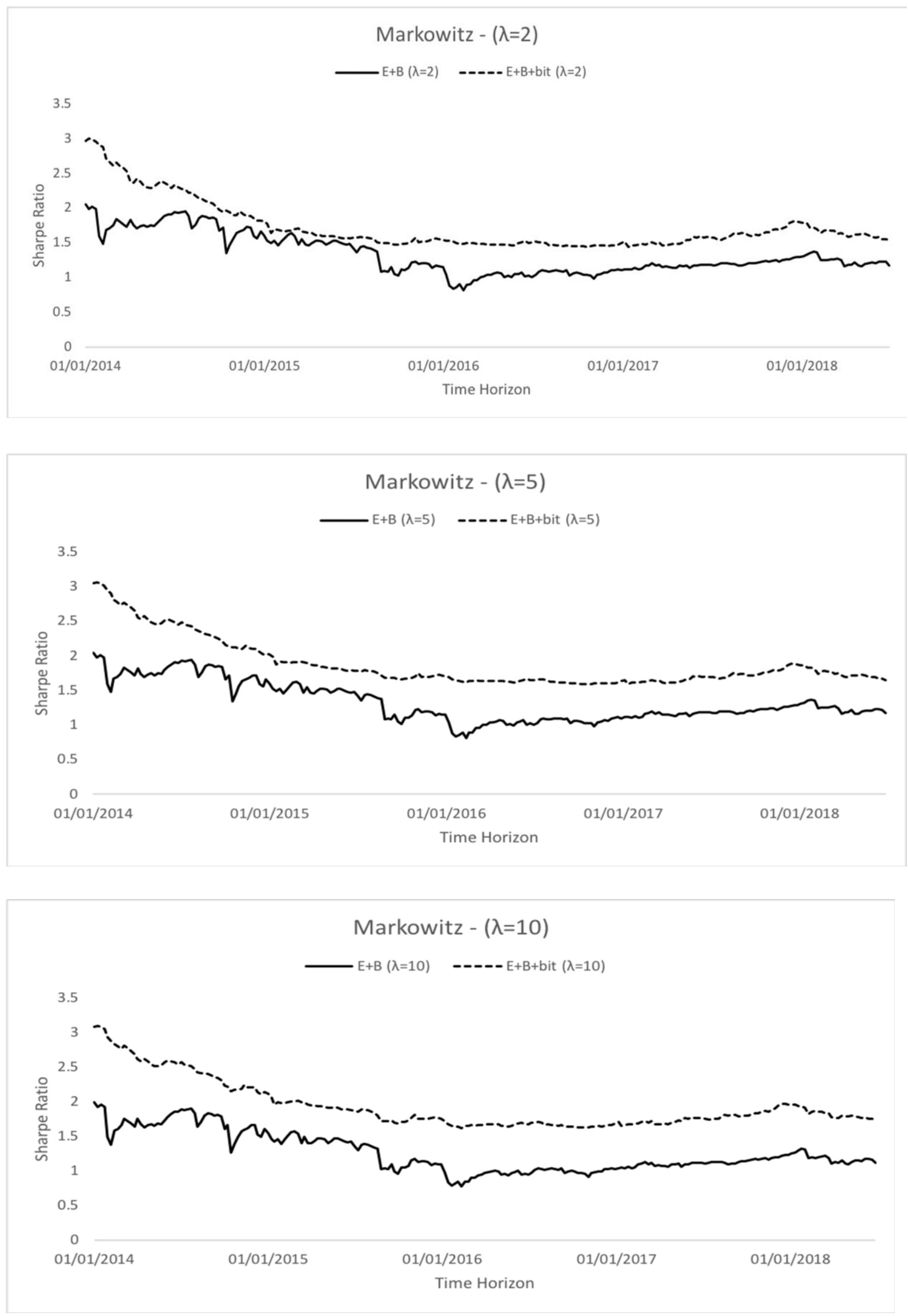